\title{
MARINE NUTRIENT SUBSIDIES TO THE TERRESTRIAL ENVIRONMENT OF COMMON EIDER NESTING COLONIES IN THE CANADIAN ARCTIC
}

\author{
By Nikolas Clyde
}

A thesis submitted to the Faculty of Graduate and Postdoctoral Affairs in partial fulfillment of the requirements for the degree of

\section{Master of Science}

in

\section{Biology}

\author{
CARLETON UNIVERSITY \\ Ottawa, Ontario \\ C Copyright Nikolas Clyde 2016
}




\begin{abstract}
Nutrient fluxes across ecosystem boundaries are thought to have pronounced effects on ecosystem dynamics, but these interactions can be difficult to confirm in complex systems. Islands are ideal for studying nutrient subsidies as they have finite boundaries. The arctic islands of Hudson Strait are severely nutrient limited, mostly undisturbed, and recovering from relatively recent glaciation. These islands support many species of seabird, including the Common Eider (Somateria mollissima), which can nest in large island colonies. Eiders forage on benthic invertebrates along coasts and return to these islands to nest. In doing so, eiders may transport marine nutrients to the terrestrial environments through excretion. These pulsed nutrient inputs during the short arctic summer may have an influence on primary productivity, trophic structure, and overall biodiversity of islands. I sampled vegetation, soil, and invertebrates on 25 islands and 6 mainland sites in the areas near Cape Dorset, Nunavut and Ivujivik, Quebec. Using stable isotope techniques, I show that nutrient subsidies from eiders to these colony islands are substantial, and have the potential to have ecosystem-level effects.
\end{abstract}




\section{Acknowledgements}

This thesis would not have been possible without the support of many people and organizations. I include a selection of them here, but there are many more than those who are listed here. Be assured I am thankful to each and every person who helped me with this project. First and foremost I would like to thank my family for providing me the chance to even attempt something like this, and for their unwavering support throughout my many trials and tribulations. I would also like to thank my two wonderful co-supervisors, Grant Gilchrist and Mark Forbes. I never conceived of doing a Master's degree until I met Grant, and his knowledge, experience and support have been instrumental in the completion of this thesis. I met Mark when I came to Carleton, and it has been a supreme pleasure getting to know him over the past 2 years. His keen comments and support are a large part of the reason I am where I am today. I have to also extend a massive thank you to Michael Janssen, Jake Russell-Mercier and the rest of the team at the NWRC, without whom I would probably still be stuck on a small island in Digges Sound rationing clif bars. I would also like to thank the Aiviq HTO and Ivujivik HTA for their support of my project. In particular, Annie Suvega of the Aiviq HTO was incredibly helpful. This project relied heavily on the expertise of local guides in Ivujivik and Cape Dorset, from whom I learned

much more than just where the islands with eiders are. I was lucky enough to have some amazing field assistants during the summer field seasons and a helpful undergrad to sort plants. I would also like to thank my collaborator Kathryn Hargan for her comments, field skills, and friendship. Finally, thanks to my friends for keeping me going and always being there for me. You know who you are. 


\section{Table of Contents}

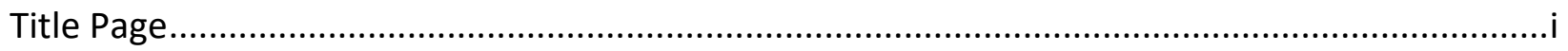

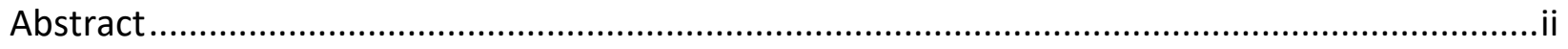

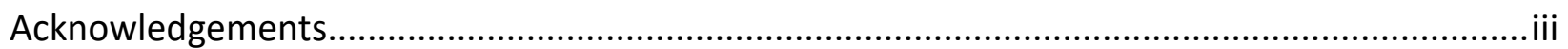

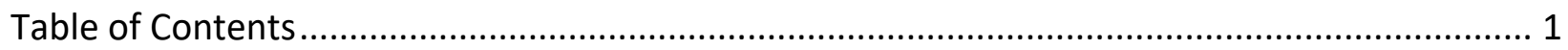

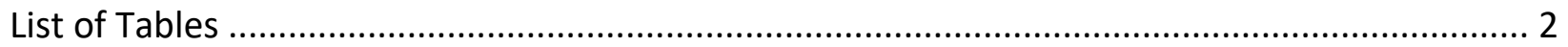

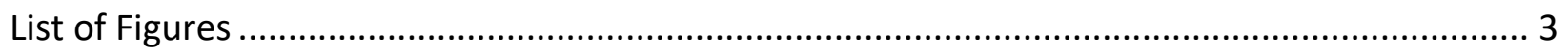

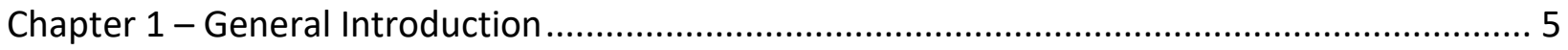

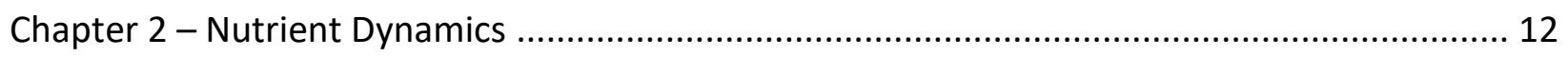

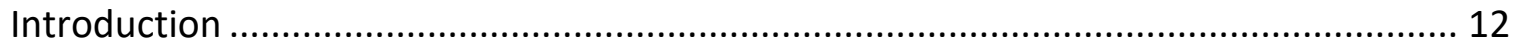

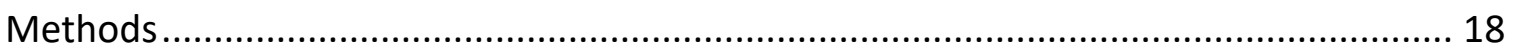

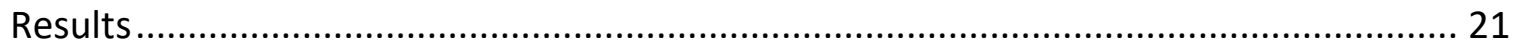

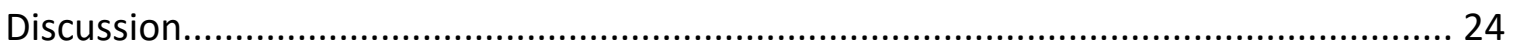

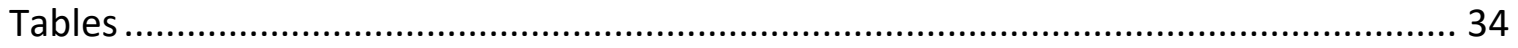

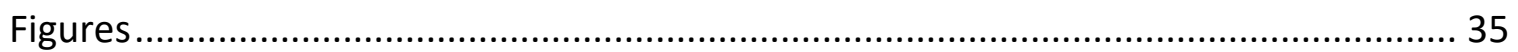

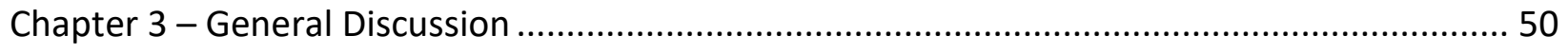

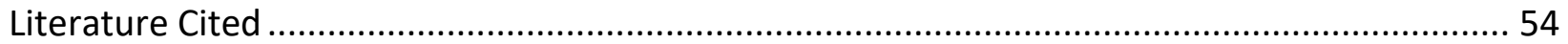




\section{List of Tables}

Table 1. List of island and mainland reference sites used for this study 


\section{List of Figures}

Figure 1. Photographs of islands in the study site depicting large variation in plant cover in relation to Common Eider nesting activity.

Figure 2. Hypothetical interactions between the Common Eider (Somateria mollissima) and their nesting island ecosystems.

Figure 3. Study site and survey locations.

Figure 4. Sampling and transect methodology on each island.

Figure 5. Differences in $\delta^{15} \mathrm{~N}$ values between colony, non-colony, and mainland sites in soil and moss samples.

Figure 6. Differences in percent nitrogen values between colony, non-colony, and mainland sites in soil and moss samples.

Figure 7. Differences in $\delta^{34} \mathrm{~S}$ values between colony, non-colony, and mainland sites in soil and moss samples.

Figure 8. The trend in $\delta^{15} \mathrm{~N}$ ratios across all sites in relation to number of active Common Eider nests.

Figure 9. The trend in percent nitrogen levels across all islands in relation to number of active Common Eider nests.

Figure 10. Differences in percent cover between colony and non-colony sites. 
Figure 11. The trend in percent cover across all islands in relation to number of active Common Eider nests.

Figure 12. The trend in percent cover within islands in relation to distance from the main pond.

Figure 13. Differences in soil depth between colony and non-colony sites.

Figure 14. The trend in soil depth across all islands in relation to number of active Common Eider nests.

Figure 15. The trend in soil depth within islands in relation to distance from the main pond. 


\section{CHAPTER 1 - GENERAL INTRODUCTION}

For a given species, there is often a range of possible habitats and patches, with some being superior in quality to others. Coupled with natural selection, this variation often leads to non-random patterns of habitat use by individuals and many studies have shown links between fitness and habitat choice (Robertson 1995, Martin 1988). For example, habitat quality is especially important for terrestrial plants. Other than during seed dispersal, terrestrial plants are limited to the immediate area where they germinate for the remainder of their existence. As such, the patch quality that they encounter after seed dispersal can have major repercussions for their fitness (Schupp 1995). For the majority of terrestrial plants, the main requirements for growth are adequate light and temperature, a source of water, nutrients, and minerals, and the availability of these factors will determine when and where communities will become established (Schupp 1995).

Ecological succession theory describes how communities are established, change over time and how the eventual 'climax' community is reached. While there is much disagreement in the field and general rules are difficult to define (Mccook 1994), there is a general acceptance that after a disturbance event, the community will be colonized by early successional species and the community will change over time as new species invade and become established. These situations are particularly interesting following catastrophic events such as volcanic eruptions or glacial periods that entirely wipe out established communities and subsequently allow for an entirely new community to develop. It is during these events in particular that small changes in 
habitat quality, species presence, and nutrient inputs can have dramatic effects on the resulting community (Lundberg and Moberg 2003).

These issues are particularly relevant in ecosystems in which species physically alter their surroundings and create, modify, or maintain habitats for themselves and other species in their community. These species are sometimes referred to as 'ecosystem engineers' (Jones et al. 1994). The most obvious example of this behavior is the dam building of the various beaver species. The formation of the dam not only creates and improves the quality of the beaver's habitat, but also fundamentally changes the structure of the river system in ways that create and destroy habitat for other species. Less obvious examples of engineering are listed by Jones et al. (1994) such as the creation of warrens by various rabbit species or the alteration of hydrology and topography by the growth of Sphagnum mosses in peat bogs. These physical state changes in the ecosystem can lead to changes in the overall community structure, especially over long time scales.

Another term applied to species that have large effects on their ecosystems is 'keystone species'. Keystone species are defined as a species whose impact on its community is disproportionally large relative to its biomass (Power et al. 1996). Although these concepts are similar, this is considered to be different than ecosystem engineering, although the case has been made that ecosystem engineers are a subset of keystone species. An ecosystem engineer may have a large effect on its community, but it does so through non-trophic regulation of a resource. Jones et al. (1994) clarify this point by using the commonly understood example of Sea Otters and urchins. In this case the otters (the keystone species) have a large effect on the community as a whole by modulating the impact of sea urchins (an ecosystem engineer) on kelp forests (another engineer). These types of interactions may be more widespread than currently 
considered and could have large impacts on ecosystem function (Jones et al. 1997, Mulder et al. 2011).

One of the key factors determining habitat quality for terrestrial plants is the presence and availability of key nutrients, including nitrogen, phosphorus and potassium (Crawford 1995). In general, increasing the availability of nutrients in an environment leads to increased plant growth; hence the importance of fertilizers in modern agriculture. Because of this dependence, nutrients entering into natural environments can have profound effects on ecosystem dynamics (Anderson and Polis 1999). This increase may be even more dramatic in environments that are severely nutrient limited, such as tundra or bog ecosystems (Shaver and Chapin 1995).

In many ecosystems, external nutrient inputs are limited and much of the available nutrient pool is generated through decomposition of plant and animal matter already present in the system. In some cases however, extra-ecosystem, or 'allochthonous' nutrients enter into the system, allowing for increased production (Polis et al. 1997). Some well-known examples include marine upwelling zones fuelling primary production, and downstream effects of river systems in which rivers transport detritus from watersheds to coastal zones. In some cases, these bottom-up nutrient subsidies can have large, ecosystem-level effects (Polis et al. 1997). Many studies have documented nutrient flows from terrestrial environments to the marine or freshwater (reviewed in Polis et al. 1997), but less have examined transport from water to land (but see Stapp et al. 1999, Reimchen and Mathewson 2002, Marczak et al. 2007)

An area of the globe characterized by low nutrient availability is Arctic Tundra. The Arctic Tundra biome is generally defined as the treeless area north of the taiga where permafrost is present year round. Tundra ecosystems are characterized by a short growing season (50-60 days), low average annual temperatures $\left(-30^{\circ} \mathrm{C}\right.$ in winter $)$, and low annual rainfall $(150-250 \mathrm{~mm})$ 
all of which limit plant growth (Pouliot et al. 2009). Primary production in much of the tundra is nutrient limited as little precipitation and low rates of decomposition lead to low levels of soluble nutrients in the shallow soil layer (Atkin 1996). In general, nitrogen is thought to be the most limiting of nutrients, and experiments in the tundra have shown large increases in plant growth following nitrogen fertilization (Shaver and Chapin 1995). Species diversity of the tundra ecosystem is also considered relatively simple when compared to other bio-regions, with around 1,700 vascular plant species. The vegetation is typically dominated by gramminoids, mosses and lichens, although some forbs and dwarf shrub species are present.

One of the animal species present in large areas of the arctic tundra is the Common Eider duck. The Common Eider (Somateria mollissima) is a long-lived sea duck with a circumpolar distribution (Goudie et al. 2000). The eiders nesting in Hudson Strait are primarily the northern race (Somateria mollissima borealis) although individuals from the Hudson Bay (S. m. sedentaria), western Arctic (S. m. v-nigrum) and Atlantic (S. m. dresseri) subspecies have also been rarely observed. Common Eiders primarily forage on marine benthic invertebrates such as mussels and urchins (generally Mytilus sp.) and usually nest on small offshore islands (Goudie et al. 2000). Cover types on these islands vary from forested areas in Maine and the Baltic Sea to tundra and polar desert environments in the Canadian Arctic (Fast 2006). Arctic-nesting eiders are considered semi-capital breeders, and therefore depend on a mix of resources acquired before reproduction to meet energetic costs of egg production and incubation (Sénéchal et al. 2011). Eider hens lay one egg per day and incubation starts after the second or third egg is laid (Swennen et al. 1993).

When eider females commence incubation, they no longer leave the colony to feed and remain on the nest $99.8 \%$ of the time, only leaving the nest to drink at nearby ponds (Bottitta et 
al. 2003). Females nesting closer to freshwater ponds have significantly higher nesting success and were also more likely to produce more ducklings (Fast 2006). This may be due to reduced predation risk when females take short breaks in incubation to drink from nearby ponds or travel with ducklings once they hatch. Ducklings with immediate access to freshwater following hatching have also been found to have greater survival (Devink et al. 2005).Females lose up to $45 \%$ of their body mass during incubation (Cantin et al. 1974, Bolduc and Guillemette 2003), so having access to a nearby source of freshwater may also help reduce energy costs by eliminating the need to actively filter salt from drinking seawater. In addition, gravid females with high wing loading often use freshwater ponds near the nesting areas as a landing site to avoid injury after tumbling among the rocks during a bad landing (Personal observation). Eiders are ground nesters and are not thought to be nest site limited, but there may be a limitation of good quality nesting islands (Fast 2006). For example, it has been shown that eiders were more likely to choose nest sites with organic substrates, suggesting a preference for such sites. These organic substrates may aid the female by providing better insulation for her eggs as well as reducing the amount of work she must invest when building a nest (Fast et al. 2010).

Arctic islands with established eider colonies appear to have more vegetation, deeper soils and greater biodiversity than islands without nesting eiders. This suggests that eiders may be enriching island habitats by transporting and depositing marine-derived nutrients onto islands through their excretion. Arctic islands that have been glaciated are otherwise nutrient limited, so eiders may be promoting organic build-up over time; essentially acting as physical and chemical engineers. These types of nutrient transports have been documented previously at specific locations (Lindeboom 1979, Anderson and Polis 1999, Mulder et al. 2011), but not on as large a geographic scale as these island archipelagos. Eiders have however been identified as ecosystem 
engineers influencing the zooplankton communities in ponds on their nesting islands in the Baltic Sea through nutrient deposition from their guano (Ebert et al. 2013).

By studying the arctic islands after glaciation, we may be able to tease apart ecological interactions, which are comparatively more complex and difficult to achieve in temperate or tropical systems. This study will contribute to understanding marine nutrient subsidies and related feedbacks in terrestrial systems, and will also provide valuable contributions to studies of marine-terrestrial nutrient subsidies and ecosystem engineering. In addition, the Common Eider is a valued food and clothing source for many northern communities in both Canada and Greenland and this study may be relevant for current and future conservation concerns as colony nesting dynamics appear to be changing in response to changes in regional sea ice dynamics (Iverson et al. 2014).

In the following chapter I will investigate how eider nutrient deposition influences both the physical and chemical structure of artic islands, with subsequent effects on the community ecology of the islands as a whole. Using accepted isotope techniques, vegetation surveys, and physical measurements of island properties, I investigate whether eiders may be acting as ecosystem engineers by altering nutrient levels in the soils and ponds on islands, leading to increased primary productivity. I hypothesize that eider ducks are transporting nutrients via guano deposition to the areas of the islands they use as colony sites, and that these areas of the islands will show the largest differences in plant and soil cover when compared to islands with no or few breeding eider ducks. This increase in primary productivity would then lead to increased accumulation of organic matter over time, which would fundamentally change the physical structure of these islands as soil, peat, and plant communities develop. This change in physical and chemical structure has the potential to influence the entire community ecology of 
islands with eider colonies, and would not have occurred on islands where eiders do not nest, leaving them little-changed since the glacial retreat following the last ice age. In areas with large concentrations of colonies, Common Eider ducks may even be considered keystone species, as their influence on the community ecology of nesting islands has the potential to be disproportionally large given the small amount of time they spend on these colonies during the short arctic summer. 


\section{CHAPTER 2 - NUTRIENT DYNAMICS}

\section{Introduction}

\section{Nutrient Subsidies and Ecosystem Functioning}

Nutrient subsidies transported by organisms (termed biological vectors) from outside a given ecosystem have been shown to have large effects on ecosystem processes in recipient communities (Anderson and Polis 1999, Mulder et al. 2011, Caut et al. 2012). These effects can range from simple increases in primary productivity to complex interactions involving multiple trophic levels. Examples of this include the transport of aquatic nutrients into forests by bears foraging on salmon (Reimchen and Mathewson 2002), the enrichment of plant communities around fox dens on their arctic breeding ground (Gharajehdaghipour et al. 2016), or the uneven nutrient subsidies provided by moose carcasses killed by wolves (Bump et al. 2016). These types of complex interactions are helping to shed light on areas of ecology that have received little attention in the past. Two key factors in how these subsidies will affect the community dynamics in the community that receives them is the type of species involved in the transport mechanism and well as the structure of the recipient community (Michelutti et al. 2009).

\section{Seabirds as vectors of Nutrients}

Seabirds have been shown to be effective bio-vectors of nutrients in many systems (Anderson and Polis 1999, Mulder et al. 2011). Through the deposition of guano, carcasses, and other detritus (such as eggshells and forage items), seabirds have the potential to alter the dynamics of the terrestrial ecosystem of their nesting islands at every level. On hyper-arid, 
nutrient poor islands in the Gulf of California for example, $\mathrm{N}$ and $\mathrm{P}$ concentrations were up to 6 times higher in soils, while nutrient levels in some plants were up to 2.4 times greater when compared to non-bird islands (Anderson and Polis 1999). In addition to looking at relative nutrient levels as an indicator of bird input, another widely used technique is to use stable isotopes of nitrogen and other elements to trace the origin of nutrients (Hobson 1999). Seabirds occupy an elevated position on the food web, hence their nitrogen signatures tend to be enriched in the heavier isotope ${ }^{15} \mathrm{~N}$ compared to ${ }^{14} \mathrm{~N}$ (Anderson and Polis 1999). In addition, the lighter

${ }^{14} \mathrm{~N}$ isotope tends to volatilize more easily in guano than the heavier ${ }^{15} \mathrm{~N}$ isotope, leading to even higher levels of ${ }^{15} \mathrm{~N}$ in guano (Mizutani et al. 1986). Using this technique, multiple studies have shown that seabird-derived nutrients can be found in many ecosystem components on islands with seabird colonies, from primary producers to tertiary consumers such as small rodents (Stapp et al. 1999, Caut et al. 2012). While they are not as commonly utilized as nitrogen isotopes, isotopes of sulphur can also be used as tracers for nutrient flows. Because of decomposition occurring under different conditions, sulphur that has originated in the marine environment will have a higher ratio of the heavier isotope ${ }^{34} \mathrm{~S}$ to the lighter ${ }^{32} \mathrm{~S}$ relative to sulphur that has originated in a terrestrial ecosystem, and can thus be used to determine the source of nutrients in a given system (Peterson and Fry 1987, Hobson 1999).

\section{Tundra Ecosystems}

Tundra ecosystems are characterized by low species diversity and simplified food webs compared to more temperate systems (Jonasson 1992). Due to this simplicity, tundra ecosystems are ideal places to study complex interactions such as allochthonous nutrient subsidies, as the effects of these subsidies could be masked in more complicated systems (Gharajehdaghipour et al. 2016). By definition, tundra systems are severely nutrient limited, so any nutrient additions 
have the potential to have very large and observable effects on the plant community (Shaver and Chapin 1995). In fact, fertilization experiments have shown that adding nutrients to tundra systems leads to both increased plant abundance and increased species diversity, a trend which is not observed in more nutrient rich environments (Fox 1992).

Island ecosystems are also ideal places to study complex interactions such as these because they have physical boundaries that simplify ecological processes (Simberloff 1974). In particular, many studies related to ecological succession rules have been carried out on islands due to their simplified structures (Whittaker \& Fernández-Palacios 2007). Arctic islands with tundra ecosystems are among the most simple of systems due to their limited biodiversity and slow rates of turnover and thus make ideal locations to study complex processes like nutrient subsidies, ecosystem engineering, and positive feedback mechanisms.

\section{Eider influence}

Common Eiders forage in the marine environment but nest on small offshore islands to facilitate the building of nests and to avoid terrestrial predators such as foxes (Goudie et al. 2000). Because of this, eiders have the potential to transport marine-derived nutrients from the highly productive coastal waters surrounding their arctic breeding sites to the severely nutrient limited terrestrial environment on their colony islands. This flux of nutrients, rich in organic $\mathrm{N}$ and $\mathrm{P}$, has the potential to fertilize the plant community, leading to increased primary productivity (Fox 1992). Because of the slow turnover and decomposition rates in tundra ecosystems, this increase in primary productivity may also lead to the accumulation of organic matter over time and the formation of soil. This build-up is evident in high-use areas on colony islands (Fig 1), and even around individual nest cups. As eiders have been shown to nest preferentially on organic substrates (Fast 2006), the build-up of organic material coupled with 
the increase in plant growth would likely lead to better nesting conditions on islands with eider colonies. These conditions have the potential to lead to positive feedback cycle (Fig 2), where eiders fertilize the landscape, in turn modifying the habitat in a manner beneficial for nesting. This would lead to more eiders becoming established and more fertilizer (guano) being deposited. This cycle, if repeated over centuries, has the potential to have multiple effects on the community and the eiders themselves.

In addition to creating better nesting habitat, the organic build-up would in turn help retain nutrients deposited by the eiders because soil and plant materials would slow and reduce nutrient loss due to run-off during rain events. This increase in available water and nutrient retention would likely benefit the plant community once again. Nutrient loading may also increase primary production in the otherwise oligotrophic pond systems (Howarth 1988). These increases in production may have effects on higher trophic level communities on these islands. For example, Hoekman et al. (2012), showed that increased productivity in colony ponds may lead to higher insect emergence from ponds, leading to the fertilization of the immediate area surrounding freshwater ponds though the deposition of nutrient rich insect carcasses.

Organic build-up on these nesting islands would also facilitate access to freshwater by increasing the depth of ephemeral ponds as accumulated peat builds up on pond margins. Many small ponds on these islands dry up entirely over the long incubation period as there is little rainfall and long hours of sunlight during the Arctic summer season. Ponds with increased depth would be more likely to persist throughout the incubation period without evaporating as their volumes would have been increased. This persistence may be especially important to eiders as Fast (2006) found a relationship between breeding success and distance to the nearest pond during incubation. This relationship was more significant at the end of the breeding season when 
females bring their ducklings to nearby ponds after hatching. Another study showed that ducklings with access to freshwater immediately after hatching had higher survival than those who were forced to drink saltwater (Devink et al. 2005). This build-up of soil would also benefit eiders by providing better nesting substrates, as eider hens nest preferentially on organic substrates (Fast et al. 2010).

These nutrient inputs and interactions may be of central importance to these island ecosystems. The Hudson Strait area is believed to have been de-glaciated around 8000 years ago (Stravers 1992), leaving what would have been barren islands scraped clean of vegetation. These islands would still have been unavailable as nesting habitat to eiders until the much more recent past as they would have been submerged due to historical sea levels and surface depression prior to isostatic rebound following the retreat of the Laurentide ice sheet. Estimates of isostatic rebound from the Hudson Bay area predict that an island 30m above sea level (ASL) today would have been completely submerged until 3000 years ago, and would only have been at an elevation of 15m ASL 1100 years ago (Stravers 1992). Allochthonous nutrient input by Common Eiders may have been integral to the formation of the diverse plant, invertebrate, and bird communities found on some of these islands today.

\section{Significance}

The Common Eider may strongly influence the ecology of many arctic islands. By transporting marine-derived nutrients to the otherwise nutrient limited terrestrial environment of their nesting islands, eiders may have provided the basic requirements for soil development and plant communities. Evidence supporting this is apparent in the stark differences in community structure between adjacent islands that have similar geographic and geologic characteristics but differ in the presence of breeding eiders. I hypothesize that the Common Eider is directly 
responsible for the environment on colony islands in the low-arctic island ecosystem with large associated effects on the community through allochthonous nutrient deposition that in turn promotes the growth of plant communities.

\section{Hypothesis}

I predict that: 1. Ecosystem components (e.g. plants, soil) on islands with eider colonies will have higher ratios of ${ }^{15} \mathrm{~N}$ and ${ }^{34} \mathrm{~S}$ than islands without eider colonies or mainland reference sites; 2. Islands supporting eider colonies have deeper soils and more abundant plant cover in areas of high eider use as compared to adjacent islands without nesting eiders; 3 . Within island variation in nutrient deposition and plant responses will match patterns of eider habitat use (i.e. will be more evident closer to areas with high nest density and other high traffic sites). 


\section{Methods}

Study site and field methods

The field portion of this work took place in two coastal locations in the Hudson Strait region of northern Canada (Fig 3). The field season was based out of Ivujivik, Quebec in the summer of 2014, and Cape Dorset, Nunavut in the summer of 2015. In both years, coastal islands were reached by boat, with the aid of local guides and assistants. Islands were chosen based on previous eider colony surveys, to attempt to survey an equal number of islands with large colonies (>200 nests) and those with little or no nesting activity. A small subset of islands with intermediate levels of nesting activity were also surveyed to determine what threshold of eider nesting effort was needed to have effects on island communities. Islands were also intentionally selected to minimize sources of other variation in basic physical criteria (distance from shore, area, elevation).

At each island in the study, a team of 3-5 people landed to complete bio-physical surveys. On islands with colonies, the team searched for the 'main pond' on each island, using apparent nest density, pond characteristics, and eider activity level as qualitative indicators. On islands with no or very little nesting activity, the largest pond furthest from the ocean was chosen. Once a selection was made, a $10 \mathrm{~cm} \times 10 \mathrm{~cm}$ sample of vegetation and soil was taken from within $2 \mathrm{~m}$ of the main pond for isotope analysis. Samples were stored in Ziploc bags and frozen upon returning to town. Four vegetation transects were also completed on each island (Fig 4). Each transect began at the edge of the main pond and continued for $30 \mathrm{~m}$ in each of the cardinal directions at $5 \mathrm{~m}$ intervals. Percent cover of all species present were recorded within a $36 \mathrm{~cm} \mathrm{x}$ 
$36 \mathrm{~cm}$ quadrat at each site. A measurement of total soil depth was made in the center of each quadrat using a piece of rebar inserted in the ground until hitting bedrock.

On one island, we took samples of moss and soil within each of the vegetation quadrats to ascertain the amount of variation in isotopic data within a representative island. We also took samples of goose and eider droppings to compare their natural isotopic signatures.

Isotope preparation and analysis

All vegetation and insect samples were manually cleaned of debris and other particles, freeze dried and homogenized using a ball mill or mortar and pestle before being analyzed for stable isotopes, with the exception of some larger insects that were analyzed whole. After homogenization, samples and standards were weighed into tin capsules and loaded into an elemental analyser (Isotope Cube, Elementar, Germany) interfaced to an isotope ratio mass spectrometer (IRMS) (Delta Advantage, Thermo, Germany) then flash combusted at $1800^{\circ} \mathrm{C}$ (Dumas combustion).The resulting gas products are carried by helium through columns of oxidizing/reducing chemicals optimised for $\mathrm{CO}_{2}$ and $\mathrm{N}_{2}$. The gases are separated by a purge and trap adsorption column and sent to the IRMS interface (Conflo III, Thermo, Germany) then to the IRMS. All analysis were performed at the G. G. Hatch Stable Isotope Lab at the University of Ottawa, Canada. The standards used in the analysis were atmospheric nitrogen $(\delta \mathrm{N})$, Cañon Diablo meteorite $(\delta \mathrm{S})$ and Pee Dee Belamnite limestone $(\delta \mathrm{C})$.

Standard isotope values were calculated using the formula:

$$
\delta=(\text { Rsample } \div(\text { Rstandard }-1)) \times 1000
$$

Where $\mathrm{R}=$ the ratio of ${ }^{15} \mathrm{~N} /{ }^{14} \mathrm{~N},{ }^{34} \mathrm{~S} /{ }^{32} \mathrm{~S}$ or ${ }^{13} \mathrm{C} /{ }^{12} \mathrm{C}$ 


\section{Data Analysis}

Islands were grouped into two treatment groups based on the number and distribution of nesting eiders, termed 'colony' and 'non-colony' (Table 1). Islands with large (>50) numbers of nesting eiders were placed in the 'colony' group, while islands with no evidence of past nesting activity were placed in the 'non-colony' group. Islands with few $(<10)$ active nests were placed in the 'no-colony' group. Islands with intermediate numbers of actively nesting eiders were excluded from categorical analyses. Data on $\delta^{15} \mathrm{~N}, \delta^{34} \mathrm{~S}$, and $\% \mathrm{~N}$ in both moss and soil were compared between the three treatment groups (mainland, colony and non-colony) using one-way ANOVAs and Tukey post-hoc tests to test for differences between groups.

I also performed linear regressions to investigate trends in isotope signatures, nutrient levels, and ecosystem response variables (such as percent cover) relative to number of active nests on islands. In all of these analyses, number of active nests was used as the independent variable, with $\delta$ values, $\%$ nitrogen, $\%$ cover, and soil depth as the response variables. Average number of active nests were used for long term response variables (such as percent cover), while recent active nests was used for response variables that have been shown to temporally variable by other studies (\%N and stable isotope values). Mainland sites were excluded from this analysis as there were no birds nesting on the mainland. All islands were included in this analysis, including those with intermediate numbers of nesting birds. Means of percent cover and soil depth for each island were calculated for pairwise comparisons to control for inflated degrees of freedom. Percent cover variables were arcsine square root transformed for statistical testing. All statistical tests were performed in Rstudio (0.00.482). 


\section{Results}

\section{Elemental Analyses}

There was significant enrichment in $\delta^{15} \mathrm{~N}(\%)$ values in soil on colony islands compared to non-colony islands and mainland reference sites. Both islands with large eider colonies and those with few nesting eider ducks had higher $\delta^{15} \mathrm{~N}$ ratios in moss compared to mainland sites (Fig 5). On colony islands there was a significant increase $(+6.2 \%)$ in $\delta^{15} \mathrm{~N}$ values in moss samples and a significant increase $(+5.71 \%)$ on non-colony islands $(\mathrm{n}=26, \mathrm{~F}=7.438, \mathrm{p}=$ $0.003)$. There was a significant increase $(+5.3 \%)$ in $\delta^{15} \mathrm{~N}$ values in soil on islands with large eider colonies, but this increase was not significant on non-colony islands $(\mathrm{n}=24, \mathrm{~F}=6.428, \mathrm{p}=$ 0.007). There were significantly higher $\% \mathrm{~N}$ values in both moss $(\mathrm{n}=26, \mathrm{~F}=4.182, \mathrm{p}=0.03)$ and soil $(n=24, F=4.743, p=0.02)$ ecosystem compartments on islands with large eider colonies compared to mainland sites, with non-colony islands falling somewhere in the middle (Fig 6). Compared to mainland sites, moss samples on islands with large colonies had 53\% more nitrogen (1.34\% vs $2.05 \%)$ and soil samples had $60 \%$ more nitrogen (1.76\% vs $2.80 \%)$.

There was a significant increase in $\delta^{34} \mathrm{~S}$ values in moss samples between islands with large eider colonies and mainland reference sites $(n=26, F=4.493, p=0.02)$, but no significant difference between non-colony islands and mainland reference sites. There was no significant difference in $\delta^{13} \mathrm{C}, \% \mathrm{C}$ or $\% \mathrm{~S}$ values between colony islands, non-colony islands and mainland reference sites.

There were higher $\delta^{15} \mathrm{~N}$ ratios in both moss and soil on islands that supported the most eider nests (Fig 8). There was a significant trend towards higher $\delta^{15} \mathrm{~N}$ ratios in moss across all sites as the number of recent active nests increased when mainland reference sites were included 
in the analysis $\left(n=26, p=0.017, R^{2}=0.19\right)$. This relationship was much improved by fitting a logarithmic decay function $\left(n=26, p=0.0007, R^{2}=0.36\right)$, as the $\delta^{15} \mathrm{~N}$ signal became saturated. The same pattern of increasing $\delta^{15} \mathrm{~N}$ ratios as the number of recent active nests increased held true for soil $\left(n=25, p=0.001, R^{2}=0.34\right)$. Piecewise regression, where multiple regression lines are fitted to different parts of the data that share similar slopes, revealed a break point of 24 nests corresponding to saturation of moss $\delta^{15} \mathrm{~N}$. These trends disappeared after removing the mainland reference sites from the analysis.

There was a nearly significant trend towards increasing $\% \mathrm{~N}$ in moss across all islands as the number of recent active nests increased $\left(n=20, p=0.07, R^{2}=0.11\right.$, Fig 9$)$. This trend was not significant in soil across all sites $\left(n=19, p=0.76, R^{2}=0.05\right)$. There was no trend in $\% C$ or $\% \mathrm{~S}$ across all sites.

As predicted, the $\delta^{15} \mathrm{~N}$ ratio of both moss $\left(\mathrm{n}=12, \mathrm{p}=0.014, \mathrm{R}^{2}=0.45\right)$ and soil $(\mathrm{n}=12$, $\mathrm{p}=0.015, \mathrm{R}^{2}=0.53$ ) was greatest around pond margins and decreased significantly as distance from the main pond increased on a colony island. Similarly, the $\% \mathrm{~N}$ values for both moss $(\mathrm{n}=$ $\left.12, \mathrm{p}=0.017, \mathrm{R}^{2}=0.42\right)$ and soil $\left(\mathrm{n}=12, \mathrm{p}=0.05, \mathrm{R}^{2}=0.37\right)$ was greatest at pond margins and declined with increasing distance from the main pond. There was no trend in $\delta^{13} \mathrm{C}$ ratios, $\delta^{34} \mathrm{~S}$ ratios, $\% \mathrm{C}$ values, or $\% \mathrm{~S}$ values across distance from the main pond.

Common Eider droppings were significantly enriched in $\delta^{15} \mathrm{~N}$ values compared to goose droppings $(+6.18 \%, \mathrm{n}=11, \mathrm{df}=4.11, \mathrm{p}=0.002)$. Thus, Common Eider droppings had similar $\delta^{15} \mathrm{~N}$ values to the ecosystem components measured on colony islands $\left(\delta^{15} \mathrm{~N}\right.$ droppings $=$ $10.09 \%$, moss $=8.29 \%$, soil $=9.71 \%$ ). Goose droppings were significantly enriched in $\delta^{34} \mathrm{~S}$ compared to eider droppings $(+3.83 \%, \mathrm{n}=11, \mathrm{df}=4.10, \mathrm{p}=0.02)$, however values for eider 
droppings were closer to ecosystem components on colony islands than goose droppings $\left(\delta^{34} \mathrm{~S}\right.$ eider droppings $=16.54 \%$, goose droppings $=20.37 \%$, moss $=17.93 \%$, soil $=15.17 \%$ ).

\section{Ecosystem Variables}

There was significantly more plant cover within transects on colony islands than on noncolony islands $(+35.8 \%, \mathrm{n}=20, \mathrm{df}=16.87, \mathrm{p}<0.001$, Fig 10$)$. There was also a significant trend of increasing average plant cover across all sites with increasing average active nests $(n=20, p=$ $\left.0.001, \mathrm{R}^{2}=0.65\right)$. Within islands, there was also a significant decrease in plant cover with increasing distance from the main pond on each colony $\left(n=606, p<0.001, R^{2}=0.14\right)$, while there was no relationship with distance to large ponds on non-colony islands $(n=231, p=0.39$, $\mathrm{R}^{2}=0.001$, Fig 12).

There was significantly deeper peat cover within transects on colony islands supporting eiders than on nearby non-colony islands $(+5.72 \mathrm{~cm}, \mathrm{n}=21, \mathrm{df}=15.08, \mathrm{p}<0.001$, Fig 13). There was also a significant trend of increasing average peat depth across all sites with increasing average active nests $\left(n=20, p<0.001, R^{2}=0.41\right.$, Fig 14). Within islands, there was a significant decrease in peat depth with increasing distance from the main pond in each colony (n $\left.=747, \mathrm{p}<0.001, \mathrm{R}^{2}=0.15\right)$, while there was no relationship with distance to large ponds on non-colony islands $\left(\mathrm{n}=422, \mathrm{p}=0.90, \mathrm{R}^{2}=0.004\right.$, Fig 15). 


\section{Discussion}

\section{Elemental Analyses}

The results of the multi-isotope approach and elemental analyses point to the presence of isotopically enriched nutrient pools on islands supporting large Common Eider nesting colonies. Both $\delta^{15} \mathrm{~N}$ values in soil and vegetation samples from colony islands were significantly enriched compared to mainland reference sites (Fig 5), indicating nutrient input from a trophically elevated source. Seabirds forage at high trophic levels and have been shown to be responsible for increases in $\delta^{15} \mathrm{~N}$ values in other systems (Anderson and Polis 1999, Caut et al. 2012). While Common Eiders are not positioned as high as other seabirds on the trophic web, eiders forage on benthic invertebrates (Goudie et al. 2000) and thus could be responsible for the input of trophically enriched nitrogen onto colony islands. In fact, $\delta^{15} \mathrm{~N}$ values measured in common eider droppings were similar to those found in ecosystem components on colony islands $\left(\delta^{15} \mathrm{~N}\right.$ droppings $=10.09 \%$, moss $=8.29 \%$, soil $=9.71 \%$ ), and significantly more enriched than Canada Goose droppings, another potential source of nutrients to these island communities. These results align well with the hypothesis that eiders transport nutrients to these islands. Insects on colony islands had similar $\delta^{15} \mathrm{~N}$ values to eider droppings (11.80\%), but we were unable to collect enough insects on reference islands for comparison. Caut et al. (2012) found similar, but higher $\delta^{15} \mathrm{~N}$ values in insects on seabird islands, but this discrepancy is likely because the colonies they were working at were of seabirds that all occupy higher trophic positions than eiders. An interesting and unexpected finding was that $\delta^{15} \mathrm{~N}$ values were also elevated on non-colony islands. One explanation for this result is the possibility that even a very small number of eider ducks are capable of transporting enough nutrients to these islands to be detected by our analysis. This is a possibility, as even non-colony islands have a small number of 
birds nesting on them. Further to this point, I had to actively search for vegetation on non-colony islands, so I was unintentionally biasing my samples to areas that had some level of nutrient availability.

$\delta^{15} \mathrm{~N}$ values increased with increasing colony size, with the signal eventually becoming saturated and no longer increasing at nearly as high of a rate at 24 nests (Fig 8). This suggests that eider isotope enrichment reaches maximum penetration of the nutrient pool at a fairly low number of nests over time. This matches the findings of Caut et al. (2012), who noted $\delta^{15} \mathrm{~N}$ values at sites with intermediate numbers of nesting birds fell in between sites with high and low nesting numbers. After removing mainland reference sites from the analysis this trend disappeared, indicating that there is no difference between $\delta^{15} \mathrm{~N}$ values on islands with respect to the number of nesting birds. This is intuitive, as all eiders are feeding at the same trophic level, so adding more birds will not necessarily increase the $\delta^{15} \mathrm{~N}$ signature present once it is detectable. There were significantly higher $\delta^{34} \mathrm{~S}$ values in moss on colony islands compared to mainland reference sites, with non-colony islands falling somewhere in the middle (Fig 7). This increase in $\delta^{34} \mathrm{~S}$ values indicates a marine source of nutrients that were not present at mainland sites. Mainland sample sites were located as close, or closer to the ocean than most samples sites on islands, so sea-spray should have been similar between sites and is likely not the explanation for these results. Again, these results align well with the hypothesis that eiders transport marine nutrients to these islands. Eiders forage primarily on marine benthic invertebrates which are enriched in the heavier isotope of sulphur as they obtain their nutrients from the marine environment (Hobson 1999). $\delta^{34} \mathrm{~S}$ values in moss and soil were close to those found in eider droppings $\left(\delta^{34} \mathrm{~S}\right.$ eider droppings $=16.54 \%$, moss $=17.93 \%$, soil $\left.=15.17 \%\right)$. Goose droppings were significantly more enriched in $\delta^{34} \mathrm{~S}(20.37 \%)$ than eider droppings, which was an 
unexpected finding as geese do not forage in the marine environment. Eider droppings were still more similar with respect to $\delta^{34} \mathrm{~S}$ to those found in moss and soil on islands supporting eider colonies. As the goose droppings were collected from colony islands, it is likely that the geese were foraging on vegetation already enriched in $\delta^{34} \mathrm{~S}$ and then depositing waste on the same island.

There also appears to be variation in nutrient deposition on an intra-island scale. $\delta^{15} \mathrm{~N}$ values were highest in both soil and moss nearest the main pond, and both declined with distance away from the pond margins. This supports my hypothesis that eiders are transporting trophically enriched nutrients to colony islands through their excrement, as the main pond and the surrounding loafing areas receive the highest amount of eider guano due to the concentration of nesting birds in this area and its use as an access point to the rest of the colony (Fast 2006). Most birds use the main pond as a landing site, as gravid females have very-high wing loading and risk injury by landing on solid ground. Because of this, the main pond of each island is almost always occupied by multiple females and their mates, as well as unpaired males seeking mates. Most birds defecate upon exiting the pond (personal observation), leading to a large influx of nutrient rich droppings to this area each summer. In addition, many birds utilize the areas immediately surrounding the pond margins as loafing sites during the pre-breeding and breeding season, further adding to the deposition of nutrients in this area over time. Because of these behavioral characteristic of eider ducks, the area surrounding the main pond is likely to receive the highest amount of guano deposition. Another potential source of the increase in $\delta^{15} \mathrm{~N}$ values near ponds is the deposition of arthropod carcasses such as midges that emerge from the freshwater ponds (Hoekman et al. 2012). This is unlikely to be the sole source of this in my system, as the lakes studied by Hoekman et al had immense densities of arthropods (lake Myvatin translates to 'lake 
of the midges') and the $\delta^{15} \mathrm{~N}$ values they obtained from plant tissues were much lower than I

found. In addition, the elevated ${ }^{34} \mathrm{~S}$ values that I measured suggest marine input that would not be present if the source was only arthropods emerging from freshwater ponds. Therefore I suggest that it is possible that arthropods emerging from the ponds on colony islands are adding nutrients to the surrounding areas, but these nutrients would likely be eider-transported nutrients to begin with.

\section{Nutrient levels}

Percent nitrogen levels in soil and vegetation samples from colony islands were also significantly higher on eider nesting colonies compared to mainland reference sites, with noncolony islands falling somewhere in the middle (Fig 6). Soil samples from colony islands were on average $52 \%$ enriched in $\mathrm{N}$ compared to reference sites while moss samples were enriched $60 \%$. For example on one colony island there was a $5 \mathrm{x}$ enrichment in $\% \mathrm{~N}$ in moss samples compared to the lowest mainland reference site. Other studies have found remarkably similar results. Anderson and Polis (1999) found 55-145\% N enrichment on desert islands in the Gulf of California, while Smith (1978) found plants influenced by seabirds were 55\% more enriched in $\mathrm{N}$ on high-latitude Marion Island. These results once again align well with my hypothesis that eider ducks are transporting marine derived nitrogen to islands where they nest. This increase in $\% \mathrm{~N}$ levels in soil and moss on islands with large numbers of nesting ducks is likely a function of scale; only a few birds are needed to modify the $\delta^{15} \mathrm{~N}$ signature, as seen on non-colony islands, but it takes a large number of birds to transport enough guano in order to see a response in the actual nutrient levels in the plant and soil components, a phenomenon only seen on islands with large colonies. 
Percent $\mathrm{N}$ levels in moss increased with increasing active recent nests $\left(\mathrm{p}=0.008, \mathrm{R}^{2}=\right.$ 0.23 ), while $\% \mathrm{~N}$ values in soil samples showed a non-significant linear trend with increasing active nests $\left(\mathrm{p}=0.11, \mathrm{R}^{2}=0.06\right)$. Both of these trends became non-significant after removing mainland reference sites from the analysis (Fig 9), although the trend was nearly significant in moss. While puzzling at first, these differences in \%N levels in plants and soil are in line with a recent fertilization study carried out on Bylot Island, Nunavut, that showed moss carpets act to constrain the effects of added fertilizers by absorbing deposited nutrients before the nutrients can penetrate to the soil below (Pouliot et al. 2009).

\section{Ecosystem Variables}

Percent cover of vegetation was significantly correlated with eider nesting numbers across islands and even within islands themselves. Colony islands had on average 12x more vegetative cover than reference (non-eider) islands ( $38.9 \%$ vs. $3.1 \%$ respectively, Fig 10 ), and this trend increased linearly with increasing average numbers of nesting females $(n=20, p=$ $0.002, \mathrm{R}^{2}=0.65$, Fig 11). These results all support the hypothesis that nutrients transported from the marine environment by eiders to islands with colonies have a large effect on plant abundance. This also supports work by Maron et al. (2006), who showed that plant communities were drastically altered on islands that failed to receive nutrient subsidies from seabirds after the introduction of foxes by humans. In my study, plant cover was most strongly associated with distance to the main pond (or ponds) on each island. On colony islands, plant cover was always highest near the pond margins and declined with increasing linear distance away from pond margins $\left(n=606, p<0.001, R^{2}=0.13\right)$. By contrast, there was no significant trend related to distance from largest pond on reference sites (Fig 12). These results suggest that highly-utilized areas of colony islands, such as the main pond margins and the surrounding loafing areas, 
accumulate the most nutrients through eider-mediated transport. Caut et al. (2012) found similar results related to the limited spatial extent of seabird-transported nutrients on islands, noting that there were significant differences in $\delta^{15} \mathrm{~N}$ and $\% \mathrm{~N}$ in sites as close as $50 \mathrm{~m}$. These findings also suggest that proximity to a body of water alone is unlikely the cause of the increased vegetation nearest to large ponds on colony islands, as the proximity to pond had little effect on vegetation growth on non-eider islands. It is clear from the limited explanatory power of the linear model that there are many more factors influencing the growth of vegetation on colony islands, including microclimate, soil properties, and substrate type. Nonetheless, nutrients appear to play a key role in promoting soil depth and plant growth.

Soil depth was also significantly correlated with eider nesting activity across sites and within sites. Soil depths were significantly higher on islands supporting eiders compared to reference islands (Fig 13). Average soil depths were 96x deeper on colony islands than on reference islands $(5.79 \mathrm{~cm}$ vs. $0.06 \mathrm{~cm})$ and this trend increased linearly across all sites in relation to nesting activity $\left(n=21, p<0.001, R^{2}=0.41\right.$, Fig 14$)$. These results suggest that eider nesting activity over time contributes to the formation of soil on islands. Within islands, soil depth followed the same trend as percent cover. On colony islands the deepest soils were consistently found adjacent to the main pond, while there was no relationship between distance from ponds and soil depth on reference islands (Fig 15). These results suggest that eidertransported nutrients lead to the accumulation of significant amounts of soil on colony islands in high-use areas like ponds and the surrounding loafing areas.

This accumulation of soil is significant in relation to the hydrology of the islands as well as eider natural history, and has the potential to lead to multiple positive feedback cycles within the community ecology of islands with nesting eider ducks. As this soil builds up, nutrients 
deposited by nesting birds would be less likely to run off in rainfall events, leading to the increased nutrient retention (Dunnett et al. 2008). This increased retention of nutrients would again promote the growth of plants and other primary producers on islands with nesting eider ducks. This promotion of plant growth would in turn increase the rates of organic deposition and soil formation over long time scales. In addition, as the soil depths increase in the immediate areas around ponds, the depth of the ponds would increase as long as the rate of sedimentation within the pond was lower than the rate of soil formation outside the pond. The increased soil layer on islands with nesting eiders would also help retain moisture independent of the depth of the pond by absorbing water that would have otherwise run off the bare rocks below. This increase in retention of water and nutrient would also lead to better conditions for plant growth, as moss carpets have been shown to absorb water during rainfall events and then slowly release it over time.

The combination of both of these factors would help small ephemeral ponds that would normally evaporate over the typically dry arctic summer persist throughout the entire eider breeding season. This persistence of ponds is relevant to nesting eider females for three reasons. First, gravid eider females often use these ponds as landing sites to avoid crash-landing and possible injury. Eider females are at their heaviest at this time of year as they must have deposited enough energetic reserves to make it through the entire incubation period without eating. Females that land in areas without ponds often tumble into rocks and other obstacles after a bad landing (Pers. Obs.). Secondly, eider females only leave the nest for short breaks to rehydrate once incubation has commenced. Females that nest closer to freshwater ponds have been shown to have a higher likelihood of hatching chicks (Fast, 2006). If these ponds dry up during the incubation season, the female will be forced to leave her nest for longer periods of 
time, at which point the eggs are vulnerable to predation. Finally, once her ducklings have hatched, the female usually leads them to a nearby pond before guiding them to the ocean. Ducklings that have access to a source of freshwater immediately after hatch have been shown to have a higher likelihood of survival compared to those that are immediately exposed to salt water (Devink et al. 2005). The closer she is to the pond, the less time her ducklings are available to predators such as gulls and jaegers.

\section{Synthesis}

Arctic tundra ecosystems are extremely nutrient limited. This has been demonstrated by multiple fertilization experiments over the past century (Fox 1992). In these experiments, addition of $\mathrm{N}$ has been shown to be the most important factor in stimulating plant growth in tundra communities (Atkin 1996, Theodose and Bowman 1997). In some cases, the addition of N led to an increase in diversity as well as abundance of the plant community, indicating that nutrient sources have the capability to change the structure of communities as well as the overall abundance of the plant community (Fox 1992).

Seabirds have been shown to be effective bio-vectors of nutrients from marine sources to colony sites on islands in multiple studies worldwide (Michelutti et al. 2009, Keatley et al. 2011, Caut et al. 2012, Zmudczyńska-Skarbek et al. 2015). Due to the tundra ecosystem present in the Hudson Strait region the transport of marine-derived nutrients to colony islands by Common Eiders has the potential to strongly influence plant communities. Indeed, my results show that marine-derived nutrients are present in soil and vegetation on colony islands, and colony islands have much higher abundance of plants and a far more developed soil layer compared to adjacent islands with no breeding eider ducks. Many of these studies detected effects on the recipient communities (Caut et al. 2012), but most focused on a single location or more rarely, multiple 
sites with different species and dynamics, making extrapolation difficult. The present study is unique that it shows consistent ecosystem-wide effects among many islands across a large geographical area that is extremely nutrient limited. The geographic scale of this study confirms that Common Eiders nest in large numbers throughout the $720 \mathrm{~km}$ long Hudson Strait and the surrounding areas, resulting in a landscape-scale effect on primary productivity and ecosystem function across these island archipelagos.

While I recognize that this study is purely correlational, the potential for eidertransported nutrients to generate this concurrent increase in vegetation and soil cover is clear. While no studies have artificially transported seabird guano to unused islands, several studies have shown that increasing fertilization of tundra communities leads to large increases in plant growth (Fox 1992, Atkin 1996) and seabird guano has long been used as a very effective fertilizer in the agricultural world. Despite not having a positive-response experiment, a study of islands in Alaska showed that the community composition of offshore islands changed drastically following the interruption of seabird nutrient transport (Croll et al. 2005), suggesting seabird nutrient subsidies were responsible for maintaining the community structure.

This study clearly shows the potential for eider-transported nutrients to have played a major role in the development of soil and the continued functioning of the plant communities found on islands supporting nesting eider ducks. This argument is even more compelling given estimates that the Hudson Strait area only emerged from under the Laurentian ice sheet approximately 8000 years before present (Stravers 1992) and based on estimates of isostatic rebound for the area, the low-lying coastal islands would likely only have been above sea level at a height significant enough to prevent winter storms from washing islands clean of soil and vegetation for $\sim 1100$ years. Age estimates of pond sediments were limited to $600 \mathrm{YBP}$, but many 
colonies had sediments that dated to at least this age (K. Hargan, unpublished). Given that it would likely have taken hundreds of years for the initial soil to have accumulated following the arrival of the first eiders, these time scales fit well with my hypothesis that the these plant communities were created over long time scales after eider colonization. 


\section{Tables}

Table 1. List of island and mainland reference sites sampled for this study. Islands and reference sites were placed into groups based on the amount of Common Eider nesting activity. Mainland reference sites were included to provide comparisons for alternative sources of nutrients.

Colony

\begin{tabular}{lrrrrr}
\hline & Latitude & Longitude & $\begin{array}{c}\text { Active Nests } \\
\text { (Most } \\
\text { Recent) }\end{array}$ & $\begin{array}{c}\text { Active Nests } \\
\text { (Average) }\end{array}$ & SE \\
\hline A-085 & 64.2923 & -74.6488 & 225 & 225 & N/A \\
A-083 & 64.3223 & -74.6669 & 259 & 162 & 97 \\
A-135 & 64.0622 & -73.5321 & 127 & 465 & 89 \\
A-136 & 64.0852 & -73.5123 & 444 & 268 & 88 \\
A-114 & 64.2683 & -74.189 & 197 & 197 & N/A \\
A-112 & 64.2959 & -74.2679 & 251 & 139 & 113 \\
A-110 & 64.3186 & -74.3316 & 91 & 150 & 59 \\
A-108 & 64.3396 & -74.3759 & 234 & 125 & 110 \\
A-056 & 64.2832 & -75.7402 & 434 & 263 & 74 \\
A-044 & 64.2979 & -75.7871 & 141 & 81 & 26 \\
A-045 & 64.2856 & -75.7821 & 15 & 164 & 100 \\
A-054 & 64.3177 & -75.7547 & 243 & 93 & 40 \\
D-003 & 62.4312 & -78.1713 & 228 & 228 & N/A \\
D-004 & 62.4436 & -78.1506 & 212 & 212 & N/A \\
D-012 & 62.3836 & -78.185 & 230 & 147 & 56 \\
D-016 & 62.3222 & -78.1759 & 367 & 197 & 171 \\
D-022 & 62.4858 & -77.8767 & 101 & 101 & N/A \\
& & & & &
\end{tabular}

Reference

\begin{tabular}{lccrrr}
\hline \multicolumn{1}{c}{ ID } & Latitude & Longitude & $\begin{array}{c}\text { Active Nests } \\
\text { (Most } \\
\text { Recent) }\end{array}$ & $\begin{array}{c}\text { Active Nests } \\
\text { (Average) }\end{array}$ & SE \\
\hline D-007 & 62.4454 & -78.1356 & 8 & 8 & N/A \\
D-019 & 62.3381 & -78.1583 & 11 & 17 & 6 \\
A-143 & 64.1028 & -73.4571 & 6 & 6 & 1 \\
A-043 & 64.2979 & -75.807 & 3 & 10 & 7 \\
A-038 & 64.2476 & -76.2292 & 7 & 7 & N/A \\
Cape Dorset (town) & & & 0 & 0 & N/A \\
Ivujivik (town) & & & 0 & 0 & N/A \\
Baffin Reference \#1 & & & 0 & 0 & N/A \\
Baffin Reference \#2 & & & 0 & 0 & N/A \\
Baffin Reference \#3 & & & 0 & 0 & N/A
\end{tabular}




\section{Figures}

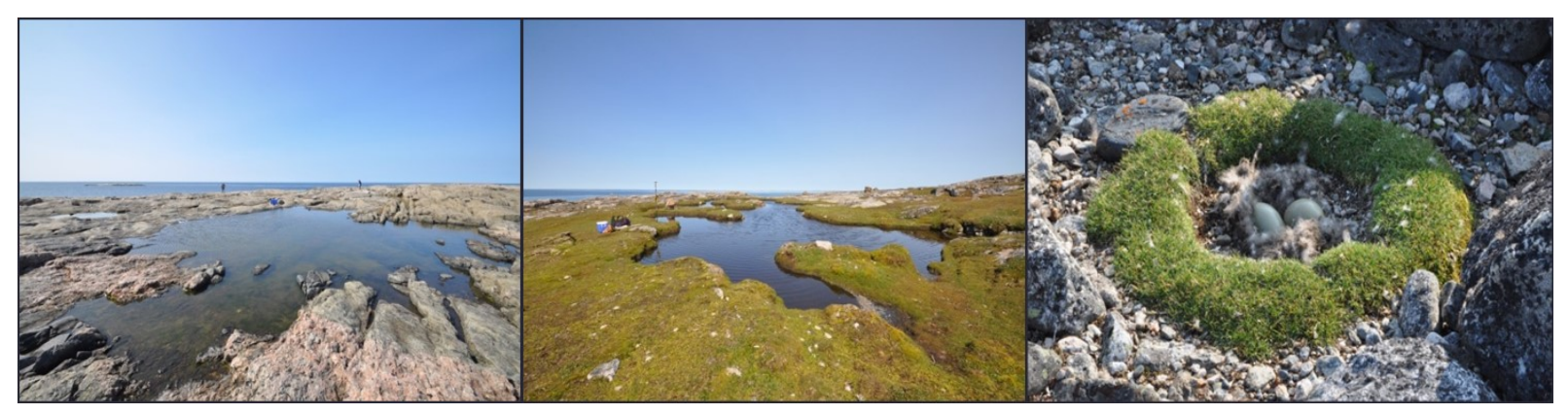

Figure 1. From left to right: A barren island lacking breeding eider ducks typical of the study area, a densely vegetated island with a large number of breeding eider ducks, and a eider duck nest cup located in a gravel bed on an island. These photos illustrate the effects that eider nesting activity has on the plant community of islands. Other than the presence of breeding eiders, the two islands pictured on the left are similar in size and distance from shore, and are located within $10 \mathrm{~km}$ of each other. 


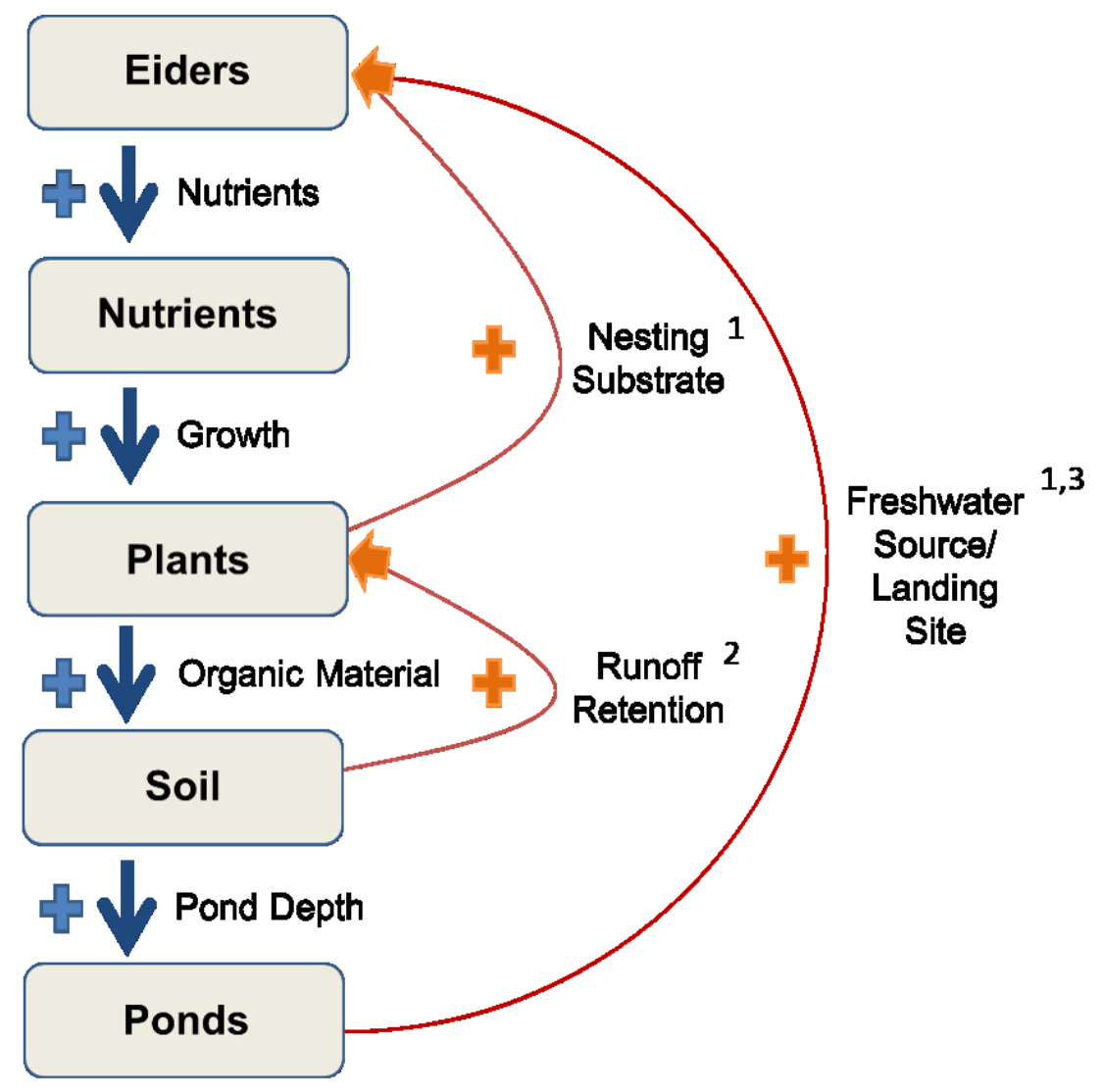

1 - Fast, P. (2006) MSc Thesis. University of Saskatchewan

2 - Barling, R. D. \& Moore, I. D. (1994) Environmental Management 18(4): 543-558

3 - Devink, A. et al. (2005) The Auk 122(2):523-529.

Figure 2. Hypothetical interactions between the Common Eider (Somateria mollissima) and their nesting island ecosystems. The introduction of marine nutrients into this terrestrial system may have substantial effects on the community ecology of the islands as a whole over time. Multiple positive feedback loops may accelerate this change. 


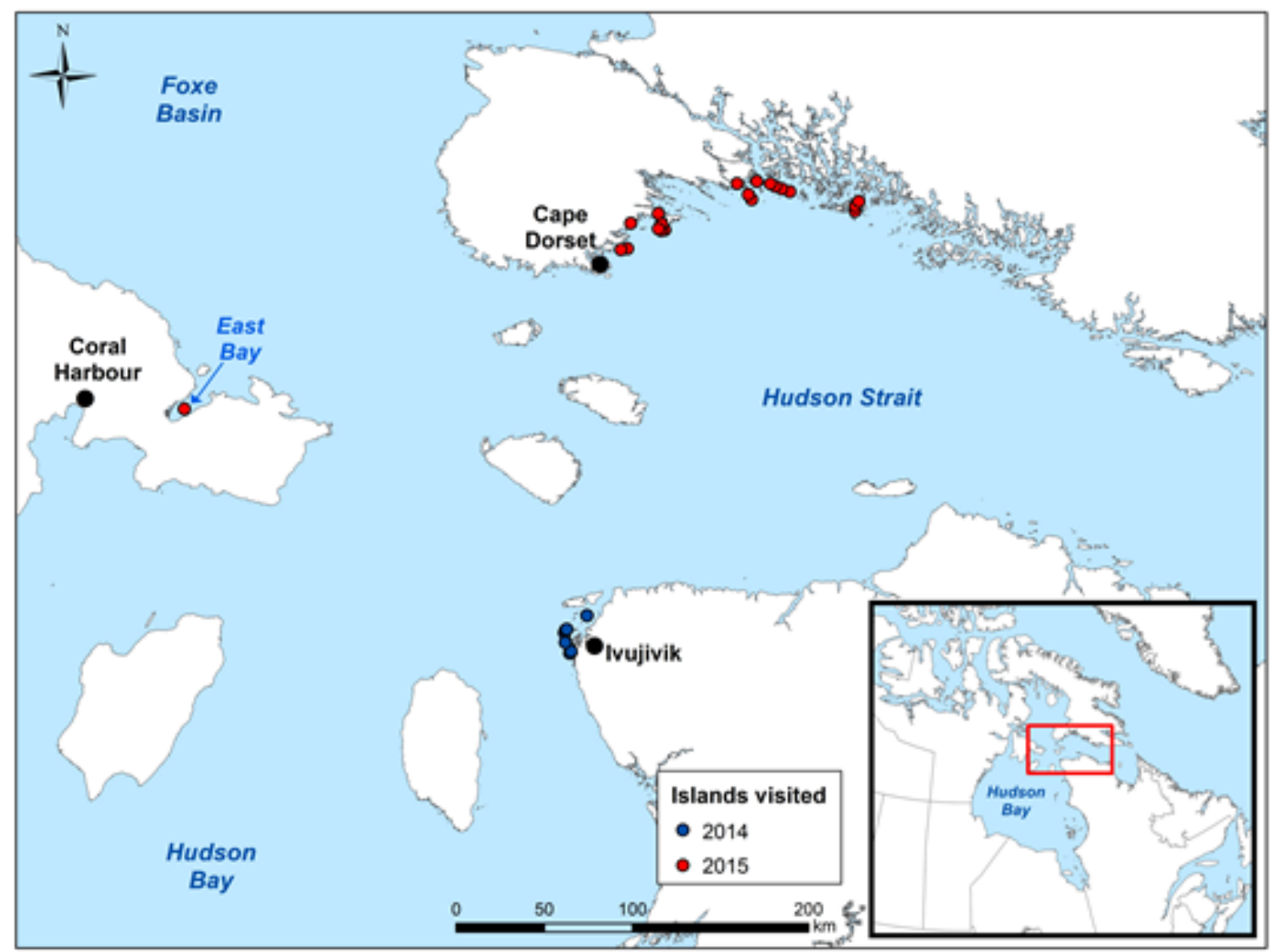

Figure 3. Study site and survey locations. The field work for this project took place over two summers in 2014 and 2015. Surveys were completed by boat with the assistance of local guides from Cape Dorset, Nunavut and Ivujivik, Quebec. Samples were also taken from the East Bay island migratory bird sanctuary in 2015 . 


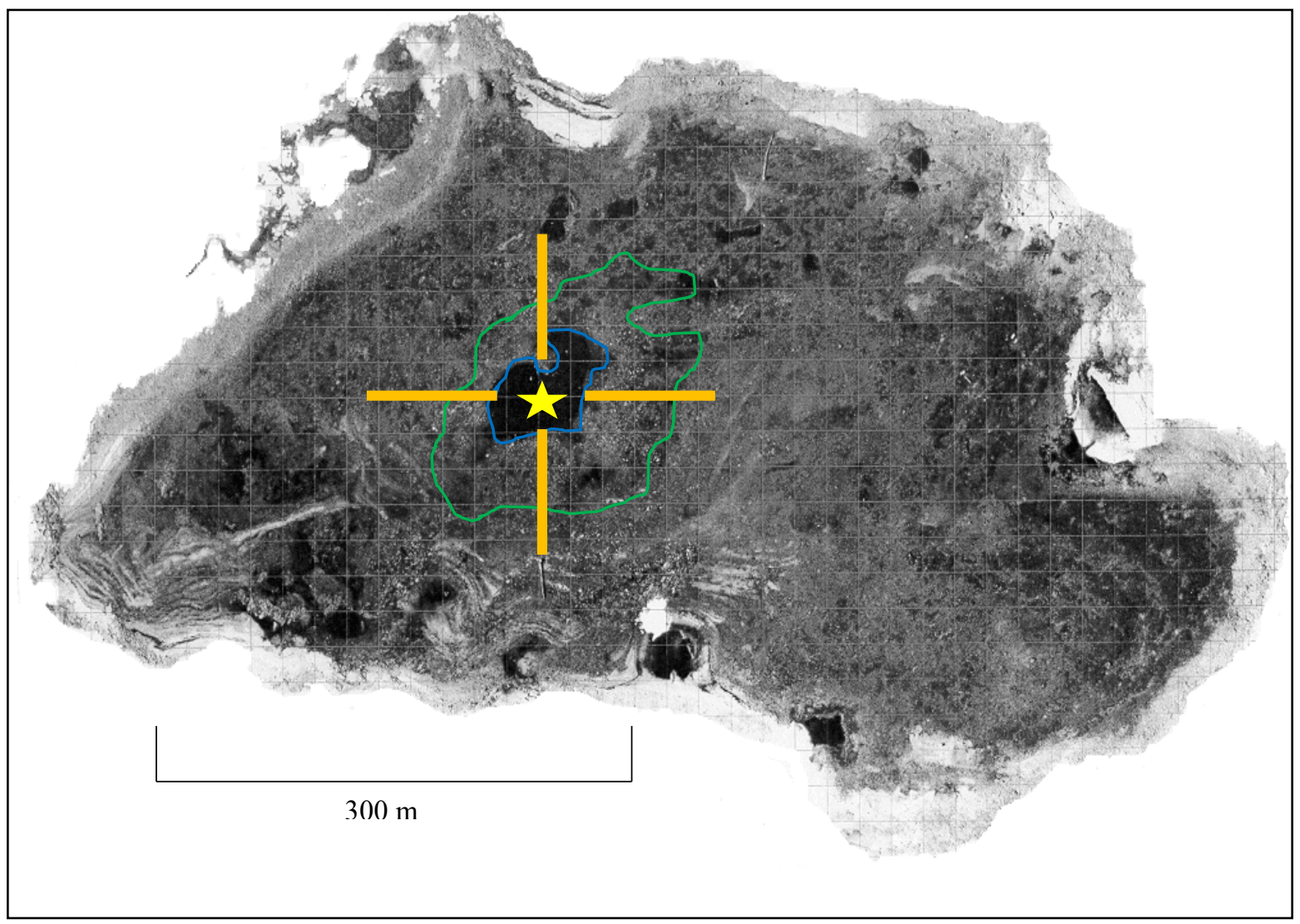

Figure 4. An example of transects surveyed on each island. On each island, four $30 \mathrm{~m}$ transects were completed radiating out from the 'main pond' in each of the cardinal directions. Percent cover and soil depth were recorded at $2.5 \mathrm{~m}$ and $5 \mathrm{~m}$ intervals. 

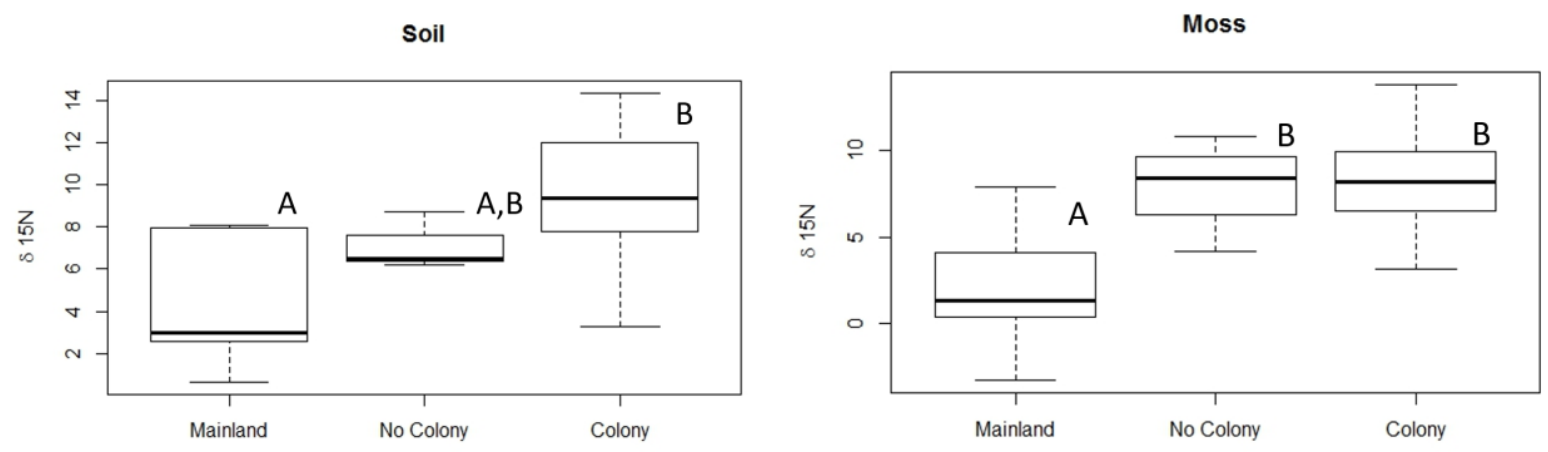

Figure 5. Differences in $\delta^{15} \mathrm{~N}$ values across the three groups. Treatment group had a significant effect on values in both soil $(\mathrm{n}=24, \mathrm{~F}=6.428, \mathrm{p}=0.007)$ and $\operatorname{moss}(\mathrm{n}=26, \mathrm{~F}=7.438, \mathrm{p}=$ 0.003). Letters indicate differences between groups: those that share a letter are not significantly different from one another. 

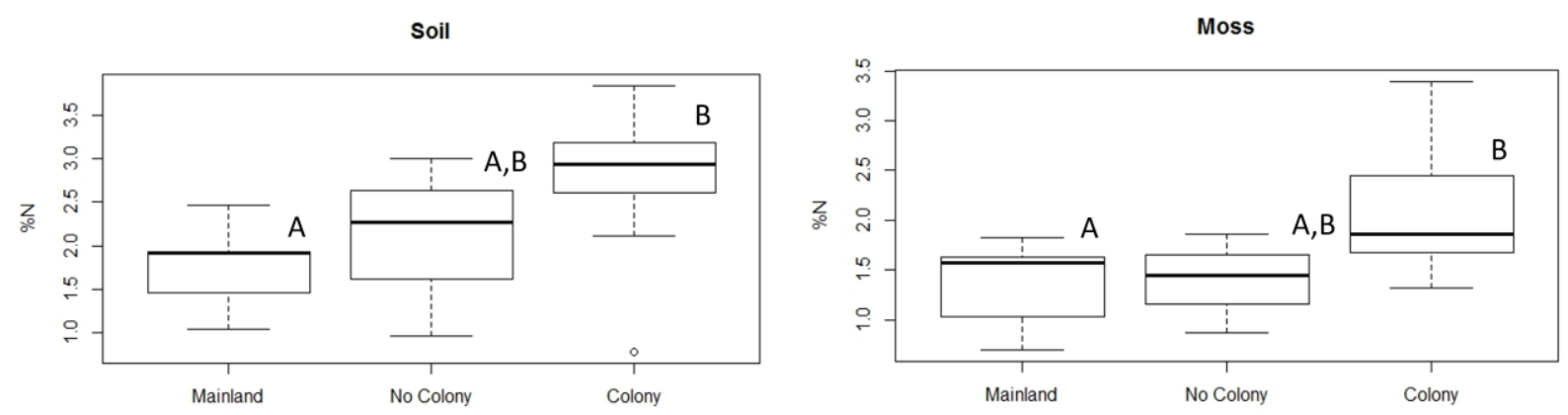

Figure 6. Differences in percent $N$ values across the three groups. Treatment group had a significant effect on values in both soil $(n=24, F=4.743, p=0.02)$ and $\operatorname{moss}(n=26, F=4.182$, $\mathrm{p}=0.03)$. Letters indicate differences between groups: those that share a letter are not significantly different from one another. 

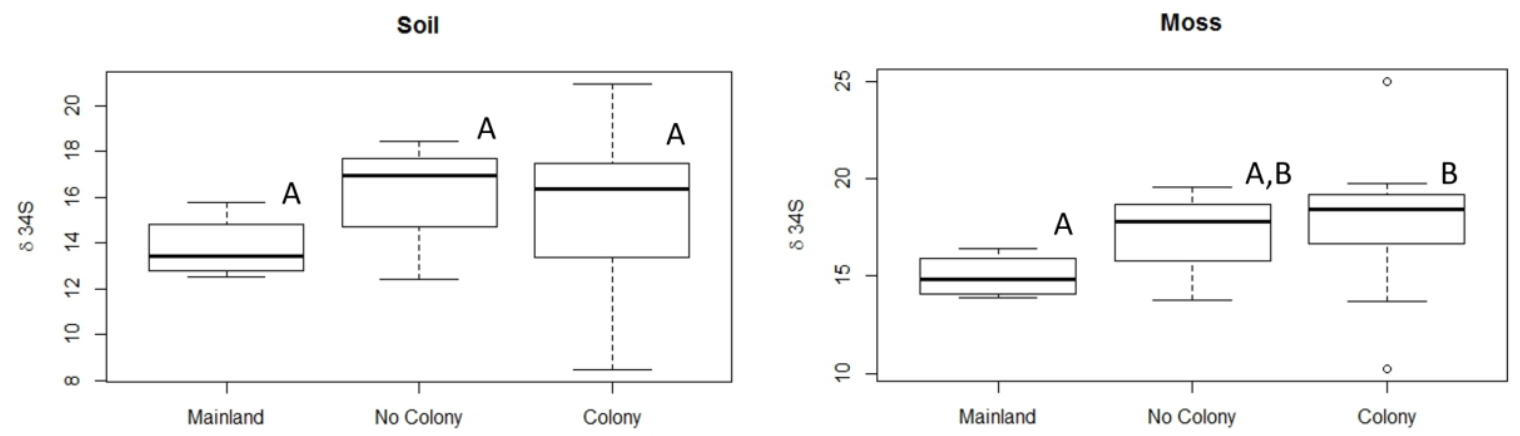

Figure 7. Differences in $\delta^{34} \mathrm{~S}$ values across the three groups. Treatment group had a significant effect on values in moss $(n=26, F=4.493, p=0.02)$, but not soil $(n=24, F=2.139, p=0.14)$. Letters indicate differences between groups: those that share a letter are not significantly different from one another. 

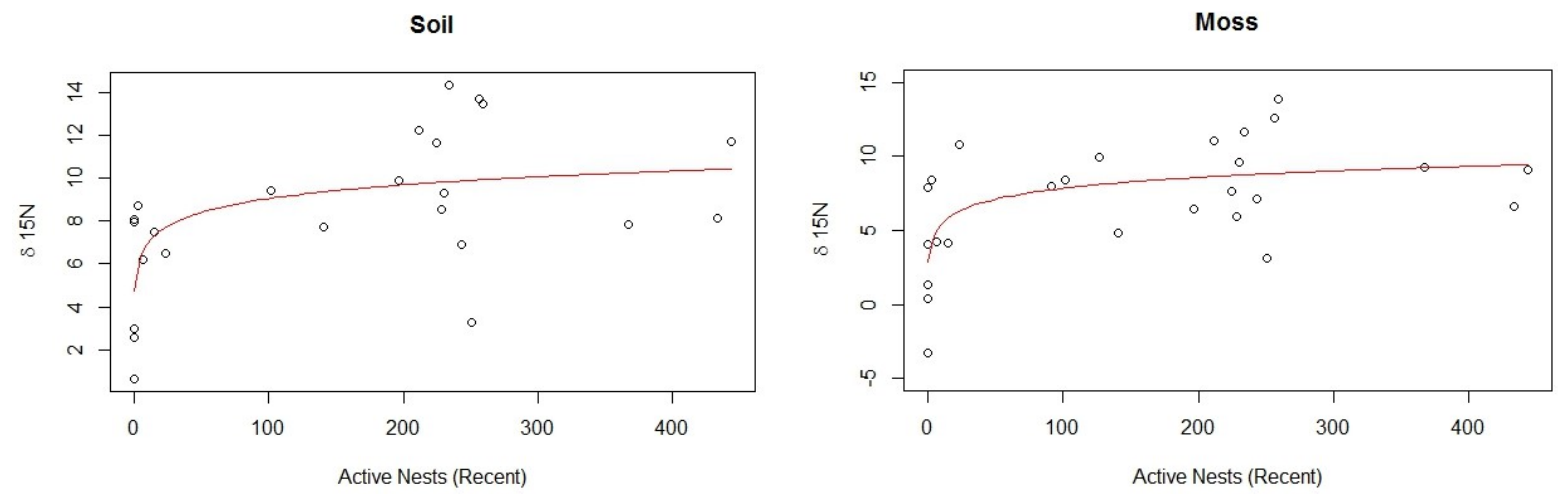

Figure 8. The trend in $\delta^{15} \mathrm{~N}$ ratios across all islands in relation to number of active Common Eider nests. There was a significant trend towards higher $\delta^{15} \mathrm{~N}$ ratios in moss across all sites as the number of recent active nests increased $\left(n=26, p=0.0007, R^{2}=0.36\right)$. The same pattern held true for soil $\left(\mathrm{n}=25, \mathrm{p}=0.001, \mathrm{R}^{2}=0.34\right)$. This trend became non-significant after removing mainland sites from the analysis. The most recent number of nests was used in this case as the level of nitrogen present in ecosystem components has been shown to be temporally variable by other studies. 

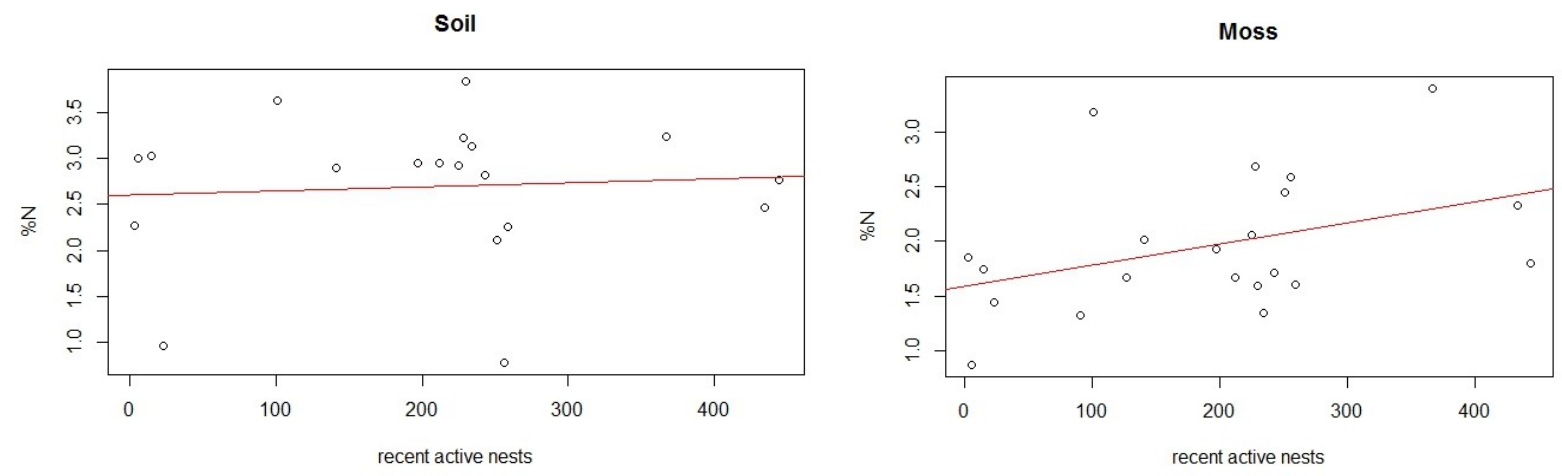

Figure 9. The trend in percent nitrogen levels across all islands in relation to number of active Common Eider nests after removing mainland reference sites from the analysis. There was no significant trend towards increasing $\% \mathrm{~N}$ in soil $\left(\mathrm{n}=19, \mathrm{p}=0.76, \mathrm{R}^{2}=0.05\right)$ or moss across all sites as the number of recent active nests increased $\left(n=20, p=0.07, R^{2}=0.11\right)$, although there was a weak trend in moss. The most recent number of nests was used in this case as the level of nitrogen present in ecosystem components has been shown to be temporally variable by other studies. 
Percent Cover

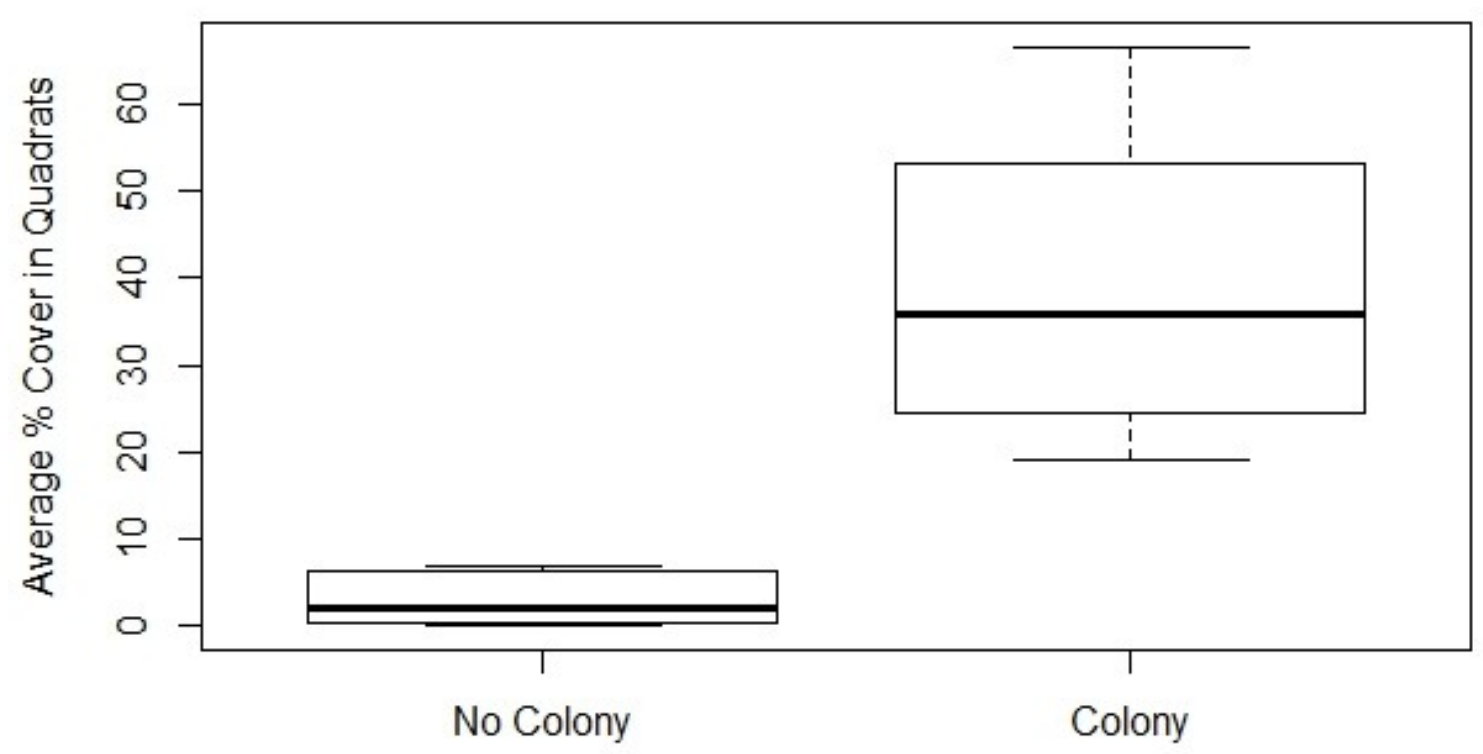

Figure 10. Differences in percent cover between colony and non-colony islands. There was significantly more plant cover within transects on colony islands than on non-colony islands $(+35.8 \%, \mathrm{n}=20, \mathrm{df}=16.87, \mathrm{p}<0.001)$. Percent cover values from each quadrat on an island were pooled and the mean was calculated for each island for this comparison. 


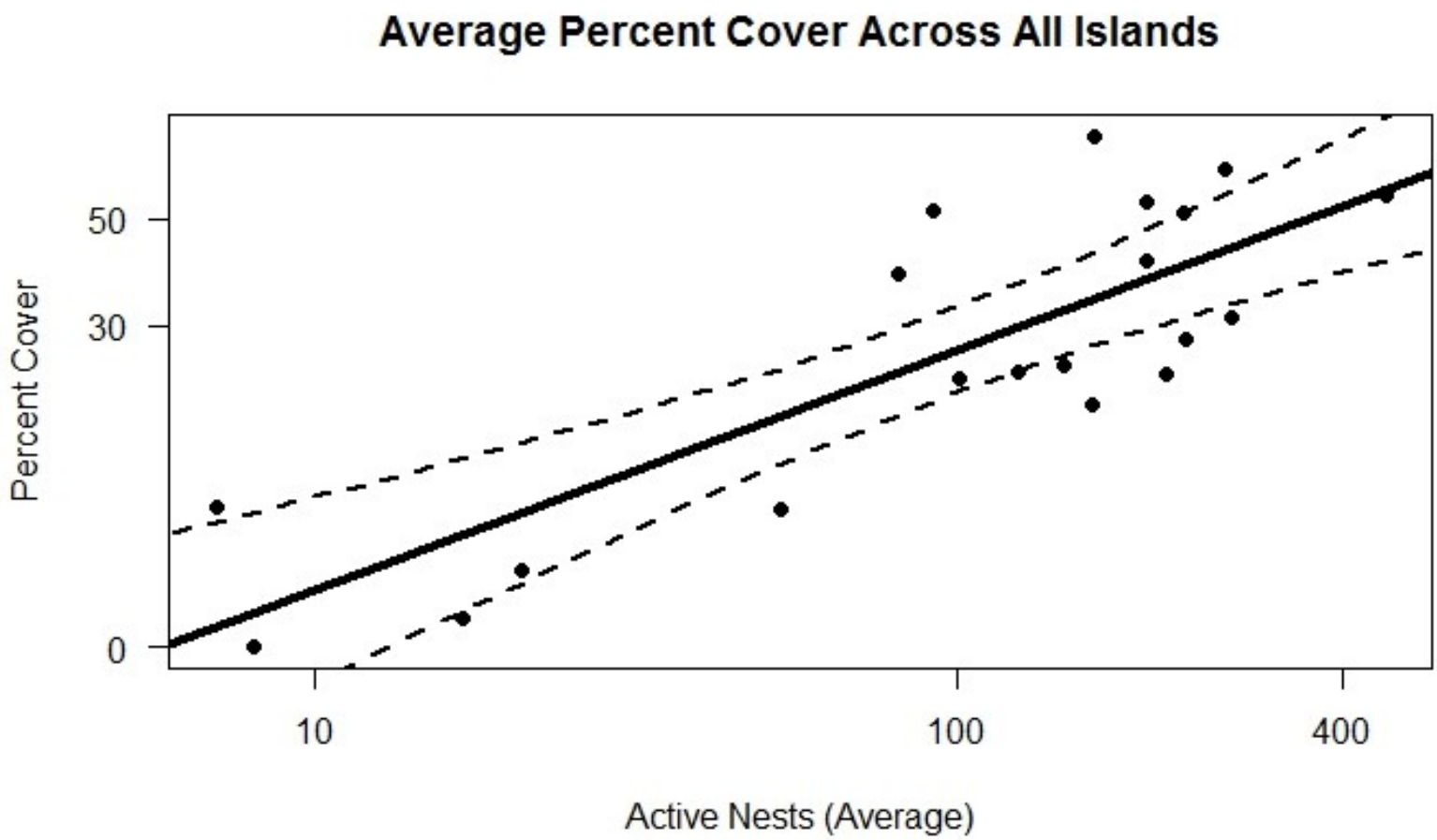

Figure 11. The trend in percent cover across all islands in relation to number of active Common Eider nests showing 95\% confidence intervals. There was a significant trend of increasing average plant cover across all sites with increasing average active nests $\left(n=20, p=0.001, R^{2}=\right.$ 0.65). The number of active nests was averaged across all years of survey data to reduce the influence of inter-annual variation in nesting numbers, as the growth of plants would have occurred over long time scales. 

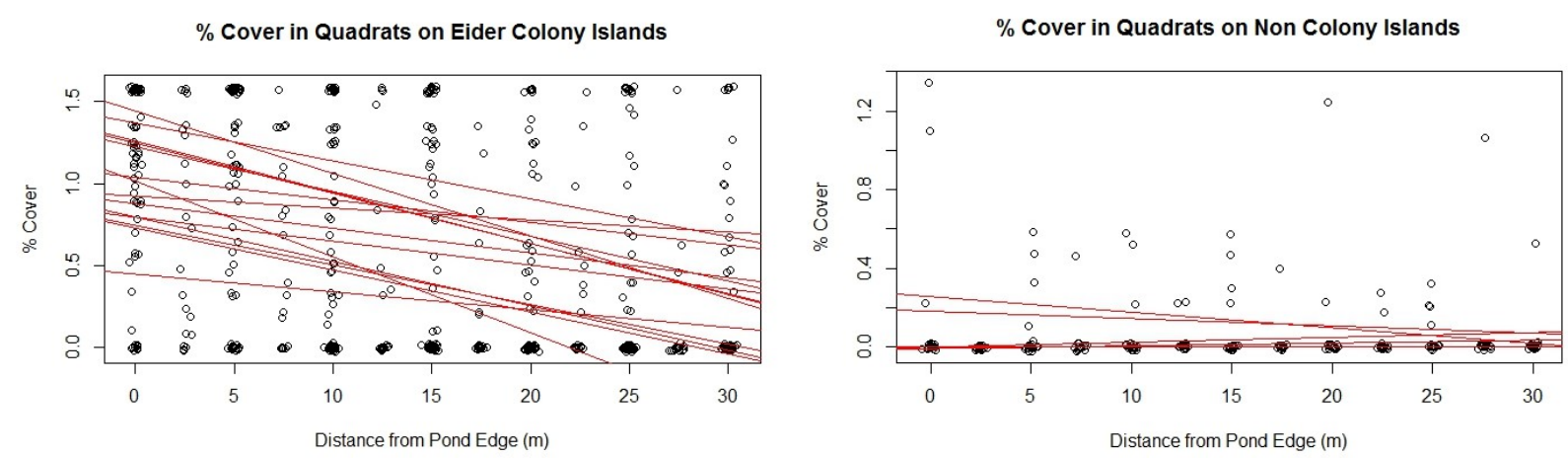

Figure 12. The trend in percent cover within islands in relation to distance from the main pond. There was a significant decrease in plant cover with increasing distance from the main pond on each colony $\left(n=606, p<0.001, R^{2}=0.14\right)$, while there was no relationship with distance to large ponds on reference islands $\left(n=231, p=0.39, R^{2}=0.001\right)$. Points have been jittered to show trends more clearly, and a trend line for each island has been shown to illustrate the common trend across both groups. 


\section{Soil Depth}

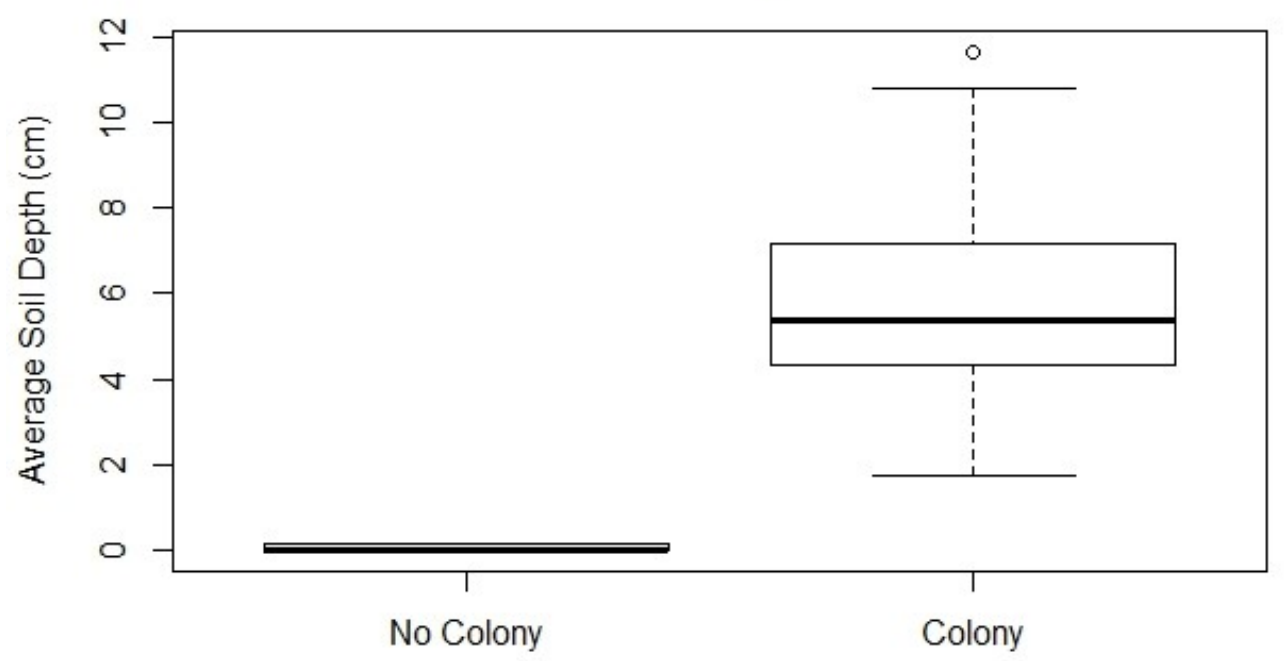

Figure 13. Differences in soil depth between colony and non-colony islands. There was significantly deeper soil within transects on colony islands supporting eiders than on nearby noncolony islands $(+5.72 \mathrm{~cm}, \mathrm{n}=21, \mathrm{df}=15.08, \mathrm{p}<0.001)$. Soil depth values from each quadrat on an island were pooled and the mean was calculated for each island for this comparison. 


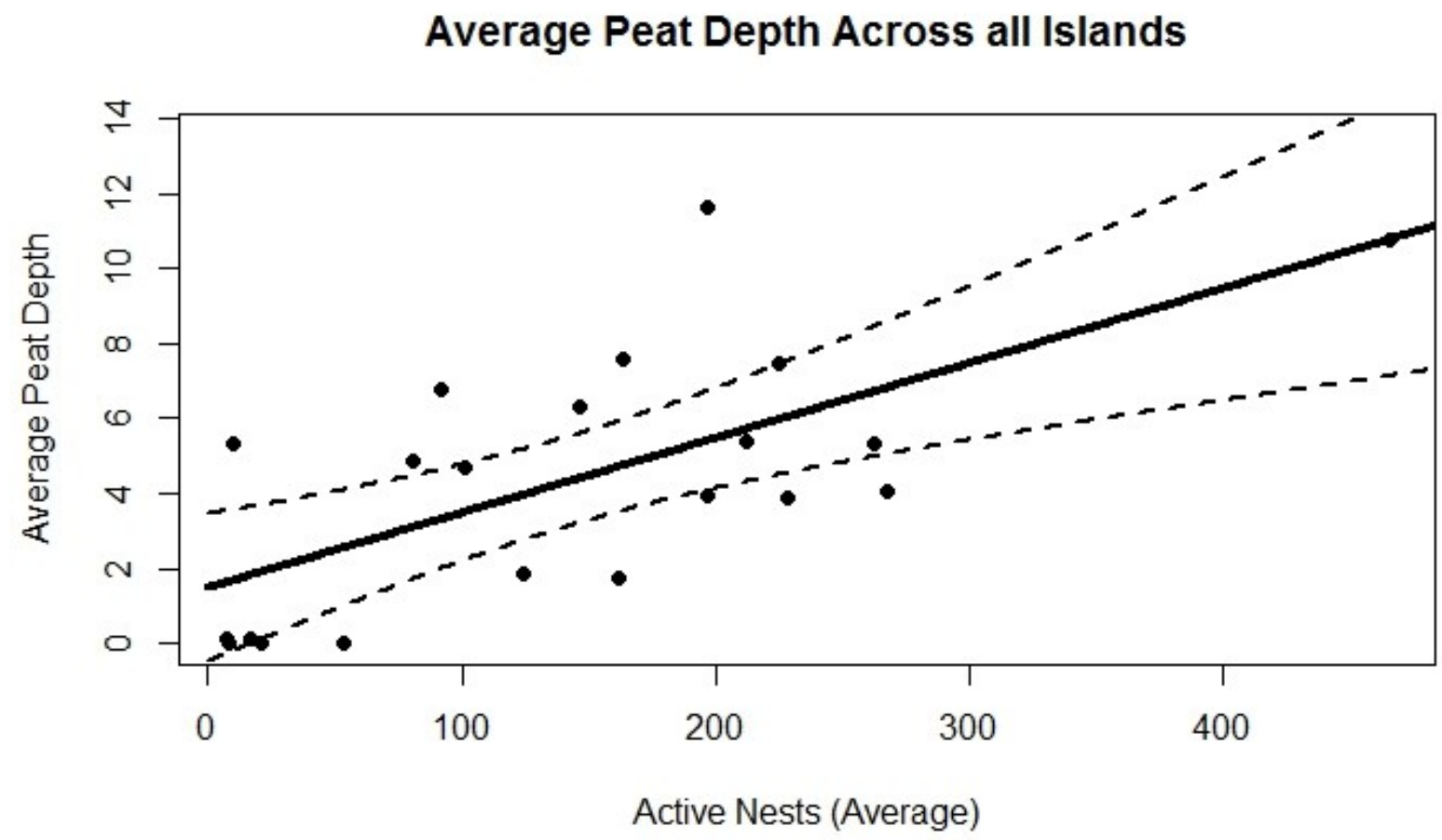

Figure 14. The trend in soil depth across all islands in relation to number of active Common Eider nests showing 95\% confidence intervals. There was a significant trend of increasing average peat depth across all sites with increasing average active nests $\left(n=20, p<0.001, R^{2}=\right.$ 0.41). The number of active nests was averaged across all years of survey data to reduce the influence of inter-annual variation in nesting numbers. 

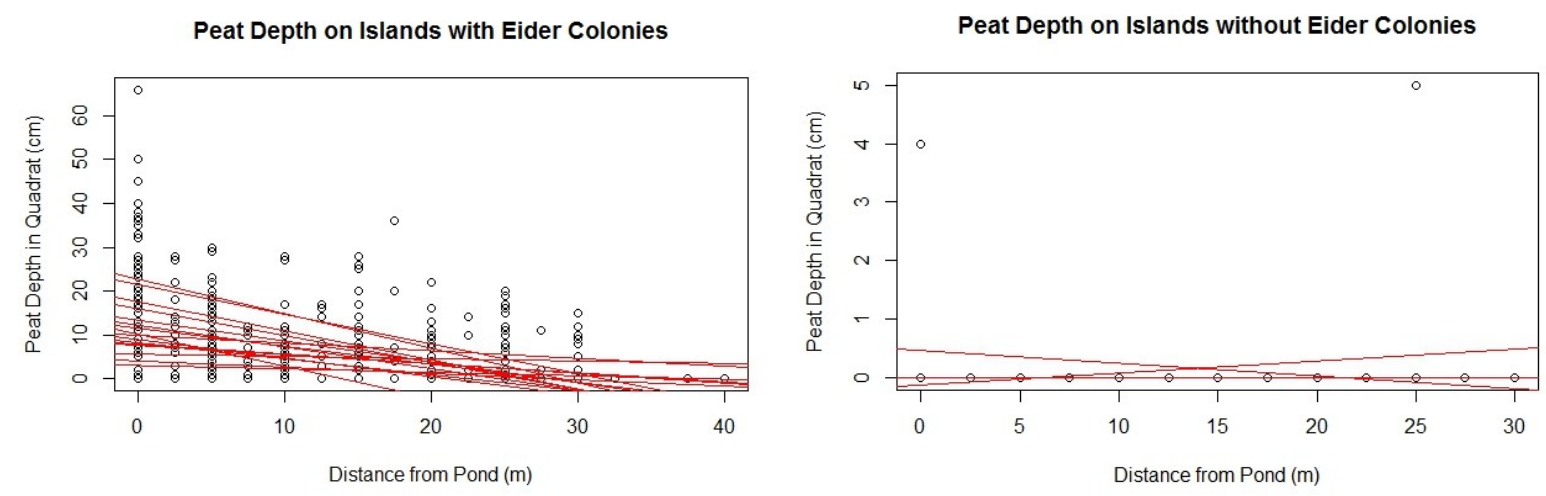

Figure 15. The trend in soil depth within islands in relation to distance from the main pond.

Within islands, there was a significant decrease in peat depth with increasing distance from the main pond in each colony ( $n=747, p<0.001, R^{2}=0.15$ ), while there was no relationship with distance to large ponds on reference islands $\left(n=422, p=0.90, R^{2}=0.004\right)$. Trend lines are shown for each island individually to illustrate the common trend across both groups. 


\section{ChaPTer 3 - General Discussion}

Using accepted isotopic techniques, my results demonstrate a significant enrichment of the terrestrial ecosystem in the immediate areas near Common Eider nesting colonies through the transport of marine-derived nutrients. In this context, eiders can be thought of as physical and chemical engineers of the entire community structure on colony islands. This enrichment appears to have the capability to affect the entire community ecology of islands utilized by nesting eider ducks, including creating conditions ideal for the success of other nesting birds. As eider ducks begin to breed on bare islands, they start to transport nutrients via guano, feathers, and other tissues. Over hundreds of years, this transport of nutrients would lead to the increased growth of plants and the concurrent increase in the rate of soil formation on areas of islands with nesting birds. This would be especially evident in areas of high eider use, such as the areas surround the main pond found at the centre of most colonies.

The phenomenon of seabirds transporting marine-derived nutrients to land has been documented before (see Anderson \& Polis 1999; Maron et al. 2006; Caut et al. 2012) but to my knowledge, this is the first time that the species in question actively benefits from the effects of the nutrient transfer. In most other studies, the subsidies provided by seabirds does not directly affect the vector species, usually because other studies have focused on cliff-nesting birds where the nutrients pool at the base of the cliff. This study is unique in that there is the potential for the positive feedback cycles identified in Fig. 2 to have modified the entire community structure of islands with nesting Common Eiders over time. In addition, this study focuses on a species at a 
lower trophic level than most other studies (but see Mallory et al. 2015), and incorporates many sites spread across a large geographical area $(\sim 750 \mathrm{~km})$.

Due to the widespread nature of eider nesting activity (Goudie et al. 2000), the results of this study have implications for any nutrient limited site at which eiders breed in numbers. As Common Eiders have a circumpolar distribution, there is a high potential for this type of interaction to be occurring at many eider breeding sites elsewhere. As such, the effects associated with eider nutrient transfer may be quite large in a pan-artic context. As an indicator of possible widespread nature of this type of interaction, past surveys of islands in Hudson Bay ( $S$. sedenteria subspecies) have been noted to have similar lush growths of moss and plant life in the areas surrounding densely nesting eiders (Nakashima and Murray 1988). Further study of similar eider colony sites in other arctic locations would be desirable in order to confirm the possible widespread effects of eider nutrient transfer on ecosystem processes in the circumpolar arctic, and to determine if the Common Eider can be considered a keystone species in the ecology of the arctic island archipelagos where they breed in large numbers.

Evidence to support the influence of eider ducks on the large landscape include observations from islands utilized by nesting eiders from across Hudson Strait and Hudson Bay indicate that there appears to be an increase in nesting Snow Buntings (Plectrophenax nivalis) when compared to nearby similar islands without nesting eider ducks, including the highest density of nesting buntings documented in the Canadian Arctic at the East Bay Island eider colony. Before fledging, bunting chicks are fed a diet of arthropods from nearby areas by their parents, and preliminary results from this study indicate a higher abundance of arthropods on islands utilized by eider ducks than on nearby un-utilized islands. By enriching the food web with increased marine-derived nutrients, eider ducks may be providing the conditions for 
increased arthropod abundance on islands with active nests. In fact, isotope values in feathers of Snow Bunting chicks grown on eider colonies have been shown to be remarkably similar to isotope values of eider tissue samples, and these values are markedly different than isotope values in feathers of chicks raised only $7 \mathrm{~km}$ away outside of the eider colony (O. Love, unpublished data). These results support the theory that nesting eider ducks influence the entire community ecology of islands where they nest.

My work has demonstrated that eiders have the potential to transform barren, glaciated islands into productive ecosystems that support an entire community that is not found on nearby islands not utilized as nesting areas by eider ducks. This process would have occurred over long time scales since the most recent glaciation, and recent studies have shown that reduced sea-ice cover in the Hudson Strait region due to climate change has led to increased predation pressure on eider colonies from Polar Bears (Iverson et al. 2014). A single bear can wipe out an entire colony in a matter of hours, and large scale colony failures due to bear predation have been observed at multiple colonies throughout Hudson Strait in recent years (H.G. Gilchrist, unpublished data). This increased predation pressure is predicted to likely cause shifts in eider nesting strategies to a more dispersed manner, and to potentially reduce eider nest numbers by up to $40 \%$ (Dey et al. 2016). As demonstrated in the Aleutian Islands (Maron et al. 2006), changing predator regimes have the potential to interrupt nutrient subsidies provided by seabirds, and the loss of these subsidies can transform the entire structure of the plant community. Given that climate change and the associated loss of sea ice is expected to continue to accelerate in polar regions, this represents a real threat to the nutrient subsidies provided by colonial nesting eiders in Hudson Strait, Hudson and Ungava Bays, and the surrounding areas. On the other hand, this interaction may lead to the formation of new colonies elsewhere, and the subsequent build-up of 
nutrients creating new habitat in previously unused territory. Considering the time scales involved in community formation and the current projections for decreased sea ice extent, increased Polar Bear predation, and reduced future eider success in the area, the conditions necessary for this process to repeat itself may however be unlikely. One possible solution to this would be to protect both current and potential eider nesting habitat from disturbance and development. Continued monitoring of eider nesting numbers, density, and location in this area is a critical next step in detecting trends in nesting strategies and breeding success relevant to predicting variation in nutrient input vectored by nesting Common Eiders. 


\section{Literature Cited}

Anderson, W., and G. Polis. 1999. Nutrient fluxes from water to land: seabirds affect plant nutrient status on Gulf of California islands. Oecologia 118:324-332.

Atkin, O. 1996. Reassessing the nitrogen relations of Arctic plants: a mini-review. Plant, Cell \& Environment 19:695-704.

Bolduc, F., and M. Guillemette. 2003. Incubation constancy and mass loss in the common eider Somateria mollissima. Ibis 145:329-332.

Bottitta, G., E. Nol, and H. Gilchrist. 2003. Effects of experimental manipulation of incubation length on behavior and body mass of common eiders in the Canadian Arctic. Waterbirds 26:100-107.

Bump, J. K., R. O. Peterson, J. A. Vucetich, J. K. Bump, R. O. Peterson, and J. A. Vucetich. 2016. Wolves Modulate Soil Nutrient Heterogeneity and Foliar Nitrogen by Configuring the Distribution of Ungulate Carcasses. Ecology 90:3159-3167.

Cantin, M., J. Bedard, and H. Milne. 1974. The food and feeding of common eiders in the St. Lawrence estuary in summer. Canadian Journal of Zoology 52:319-334.

Caut, S., E. Angulo, B. Pisanu, L. Ruffino, L. Faulquier, O. Lorvelec, J.-L. Chapuis, M. Pascal, E. Vidal, and F. Courchamp. 2012. Seabird modulations of isotopic nitrogen on islands. PloS one 7:e39125.

Crawford, N. 1995. Nitrate: nutrient and signal for plant growth. The Plant Cell 7:859-868.

Croll, D., J. Maron, J. Estes, E. Danner, and G. Byrd. 2005. Introduced predators transform subarctic islands from grassland to tundra. Science 307:1959-1962. 
Devink, J., H. G. Gilchrist, and A. W. Diamond. 2005. Effects of Water Salinity on Growth and Survival of Common Eider ( Somateria Mollissima ) Ducklings 122:523-529.

Dey, C., E. Richardson, D. Mcgeachy, S. Iverson, G. Gilchrist, and C. Semeniuk. 2016. Increasing nest predation will be insufficient to maintain polar bear body condition inthe face of sea- ice loss. Global Change Biology.

Dunnett, N., A. Nagase, R. Booth, and P. Grime. 2008. Influence of vegetation composition on runoff in two simulated green roof experiments. Urban Ecosystems 11:385-398.

Ebert, D., J. W. Hottinger, and V. I. Pajunen. 2013. Unsuitable habitat patches lead to severe underestimation of dynamics and gene flow in a zooplankton metapopulation. The Journal of animal ecology 82:759-69.

Fast, P., H. Gilchrist, and R. Clark. 2010. Nest-site materials affect nest-bowl use by Common Eiders (Somateria mollissima). Canadian Journal of Zoology.

Fast, P. L. F. 2006. Nest Site Selection by Common Eiders. University of Saskatchewan.

Fox, J. 1992. Responses of diversity and growth-form dominance to fertility in Alaskan tundra fellfield communities. Arctic and Alpine Research 24:233-237.

Gharajehdaghipour, T., J. D. Roth, P. M. Fafard, and J. H. Markham. 2016. Arctic foxes as ecosystem engineers: increased soil nutrients lead to increased plant productivity on fox dens. Scientific Reports 6:7-9.

Hobson, K. a. 1999. Tracing origins and migration of wildlife using stable isotopes: a review. Oecologia 120:314-326.

Hoekman, D., M. Bartrons, C. Gratton, D. Hoekman, and M. Bartrons. 2012. International 
Association for Ecology Ecosystem linkages revealed by experimental lake-derived isotope signal in heathland food webs. Oecologia 170:735-743.

Howarth, R. 1988. Nutrient limitation of net primary production in marine ecosystems. Annual Review of Ecology and Systematics 19:89-110.

Iverson, S., H. Gilchrist, P. Smith, A. Gaston, and M. Forbes. 2014. Longer ice-free seasons increase the risk of nest depredation by polar bears for colonial breeding birds in the Canadian Arctic. Proceedings. Biological sciences / The Royal Society.

Jonasson, S. 1992. Plant responses to fertilization and species removal in tundra related to community structure and clonality. Oikos 63:420-429.

Jones, C., J. Lawton, and M. Shachak. 1994. Organisms as ecosystem engineers. Oikos 69:373386.

Jones, C., J. Lawton, and M. Shachak. 1997. Positive and negative effects of organisms as physical ecosystem engineers. Ecology 78:1946-1957.

Keatley, B. E., J. M. Blais, M. S. V. Douglas, I. Gregory-Eaves, M. L. Mallory, N. Michelutti, and J. P. Smol. 2011. Historical seabird population dynamics and their effects on Arctic pond ecosystems: a multi-proxy paleolimnological study from Cape Vera, Devon Island, Arctic Canada. Fundamental and Applied Limnology 179:51-66.

Lindeboom, H. J. 1979. Chemical and microbiological aspects of the nitrogen cycle on Marion Island(sub-Antarctic). University of Groningen.

Lundberg, J., and F. Moberg. 2003. Mobile Link Organisms and Ecosystem Functioning: Implications for Ecosystem Resilience and Management. Ecosystems 6:87-98. 
Mallory, M. L., L. Mahon, M. D. Tomlik, C. White, G. R. Milton, and I. Spooner. 2015. Colonial Marine Birds Influence Island Soil Chemistry Through Biotransport of Trace Elements. Water, Air, \& Soil Pollution 226:31.

Marczak, L., R. Thompson, and J. Richardson. 2007. Meta-analysis: trophic level, habitat, and productivity shape the food web effects of resource subsidies. Ecology 88:140-148.

Maron, J., J. Estes, and D. Croll. 2006. An introduced predator alters Aleutian Island plant communities by thwarting nutrient subsidies. Ecological ... 76:3-24.

Martin, T. E. 1988. Habitat and Area Effects on Forest Bird Assemblages: Is Nest Predation an Influence? Ecology 69:74-84.

Mccook, L. J. 1994. Understanding ecological community succession : Causal models and theories, a review. Vegetatio:115-147.

Michelutti, N., B. E. Keatley, S. Brimble, J. M. Blais, H. Liu, M. S. V Douglas, M. L. Mallory, R. W. Macdonald, and J. P. Smol. 2009. Seabird-driven shifts in Arctic pond ecosystems. Proceedings of The Royal Society Biology 276:591-596.

Mizutani, H., Y. Kabaya, and E. Wada. 1986. Ammonia volatilization and high 15N/14N ratio in a penguin rookery in Antarctica. Geochemical Journal 19:323-327.

Mulder, C., W. Anderson, D. Towns, and P. Bellingham. 2011. Seabird Islands: Ecology, Invasion, and Restoration. Oxford University Press.

Peterson, B. J., and B. Fry. 1987. Stable Isotopes in Ecosystem Studies. Annual Reviews 18:293-320.

Polis, G., S. Hurd, C. Jackson, and F. Piñero. 1997. El Niño effects on the dynamics and control 
of anisland ecosystem in the Gulf of California. Ecology 78:1884-1897.

Pouliot, R., L. Rochefort, and G. Gauthier. 2009. Moss carpets constrain the fertilizing effects of herbivores on graminoid plants in arctic polygon fens. Botany 87:1209-1222.

Power, M., D. Tilman, J. Estes, and B. Menge. 1996. Challenges in the quest for keystones. BioScience 46:609-620.

Reimchen, T., and D. Mathewson. 2002. Isotopic evidence for enrichment of salmon-derived nutrients in vegetation, soil, and insects in riparian zones in coastal British Columbia. American Fisheries Society Symposium.

Robertson, G. 1995. Factors affecting nest site selection and nesting success in the common eider Somateria mollissima. Ibis 137:109-115.

Schupp, E. 1995. Seed-seedling conflicts, habitat choice, and patterns of plant recruitment. American Journal of Botany 82:399-409.

Sénéchal, E., J. Bêty, H. G. Gilchrist, K. a Hobson, and S. E. Jamieson. 2011. Do purely capital layers exist among flying birds? Evidence of exogenous contribution to arctic-nesting common eider eggs. Oecologia 165:593-604.

Shaver, G., and F. Chapin. 1995. Long-term responses to factorial, NPK fertilizer treatment by Alaskan wet and moist tundra sedge species. Ecography:259-275.

Simberloff, D. S. 1974. Equilibrium Theory of Island Biogeography and Ecology. Annual Review of Ecology and Systematics 5:161-182.

Stapp, P., G. Polis, and F. Piñero. 1999. Stable isotopes reveal strong marine and El Nino effects on island food webs. Nature 401:467-469. 
Stravers, J. 1992. Late glacial ice margins and deglacial chronology for southeastern Baffin Island and Hudson Strait, eastern Canadian Arctic. Canadian Journal of Earth Science 29:1000-1017.

Swennen, C., J. Ursem, and P. Duiven. 1993. Determinate laying and egg attendance in common eiders. Ornis Scandinavica 24:48-52.

Theodose, T., and W. Bowman. 1997. Nutrient availability, plant abundance, and species diversity in two alpine tundra communities. Ecology 78:1861-1872.

Zmudczyńska-Skarbek, K., P. Balazy, and P. Kuklinski. 2015. An assessment of seabird influence on Arctic coastal benthic communities. Journal of Marine Systems 144:48-56. 